\title{
Leptin Signalling in the Ovary of Diet-Induced Obese Mice Regulates Activation of Nod-Like Receptor Protein 3 Inflammasome
}

1 Marek Adamowski ${ }^{1}$, Karolina Wołodko ${ }^{1}$, Joana Oliveira ${ }^{2}$, Juan Castillo-Fernandez ${ }^{3}$, Daniel

2 Murta $^{4,5}$, Gavin Kelsey ${ }^{3,6}$, António M. Galvão ${ }^{1,3,6^{*}}$

$3 \quad{ }^{1}$ Department of Reproductive Immunology and Pathology, Institute of Animal Reproduction and

4 Food Research of Polish Academy of Sciences, Olsztyn, Poland

$5 \quad{ }^{2}$ Centro de Investigação em Ciências Veterinárias, Lusófona University, Lisbon, Portugal

$6 \quad{ }^{3}$ Epigenetics Programme, The Babraham Institute, Cambridge, CB22 3AT, UK

$7 \quad{ }^{4}$ Centro de Investigação Interdisciplinar Egas Moniz (CiiEM), Escola Superior de Saúde Egas Moniz,

8 Campus Universitário, Quinta da Granja, Monte de Caparica, Portugal

$9 \quad{ }^{5}$ C.I.I.S.A., Faculty of Veterinary Medicine, University of Lisbon, Lisbon, Portugal

$10{ }^{6}$ Centre for Trophoblast Research, University of Cambridge, Cambridge, CB2 3EG, UK

11 * Correspondence:

12 António M. Galvão

13 antonio.galvao@babraham.ac.uk

16 Keywords: ovary, inflammation, leptin, obesity, NLRP3inflammasome 


\section{Abstract}

29 Obesity leads to ovarian dysfunction and the establishment of local leptin resistance. The aim of our 30 study was to characterise levels of Nod-Like Receptor Protein 3 (NLRP3) inflammasome activation

31 during obesity progression in the mouse ovaries and liver and test the putative role of leptin on its

32 regulation. $\mathrm{C} 57 \mathrm{BL} / 6 \mathrm{~J}$ mice were treated with equine chorionic gonadotropin (eCG) or human

33 chorionic gonadotropin (hCG) for oestrous cycle synchronisation and ovaries collection. In diet-

34 induced obesity (DIO) model, mice were fed chow diet (CD) or high fat diet (HFD) for 4 or 16 weeks

35 (wk), whereas in hyperleptinemic model (LEPT), mice were injected with leptin for 16 days (16L) or

36 saline (16C) and in the genetic obese leptin-deficient $o b / o b(+/$ ? and -/-) animals were fed CD for

$374 w k$. Either ovaries and liver were collected, as well as cumulus cells (CCs) after superovulation

from DIO and LEPT. In DIO protocol, protein expression of NLRP3 inflammasome components was

39 increased in 4wk HFD, but decreased in 16wk HFD. Moreover LEPT and ob/ob models revealed

40 NLRP3 and IL-1 $\beta$ upregulation in $16 \mathrm{~L}$ and downregulation in $o b / o b$. Transcriptome analysis of CC

41 showed common genes between LEPT and 4wk HFD modulating NLRP3 inflammasome. Moreover analysis in the liver showed upregulation of NLRP3 protein only after 16wk HFD, but also the downregulation of NLRP3 protein in $o b / o b-/-$. We showed the link between leptin signalling and NLRP3 inflammasome activation in the ovary throughout obesity progression in mice, elucidating the molecular mechanisms underpinning ovarian failure in maternal obesity. 


\section{Introduction}

Obesity leads to self-directed tissue inflammation, a process mostly promoted by the continuous expansion of adipose tissue (Hotamisligil and Erbay 2008; Odegaard and Chawla 2008).

Furthermore, literature presents a solid link between obesity and reproductive failure in women (Chu

et al. 2007). Indeed, obesity in women has been associated to ovarian dysfunction, embryo

metabolic dysfunction (Chu et al. 2007; Penzias 2012; Robker 2008; Samuelsson et al. 2008). The

(Jungheim et al. 2010). Furthermore, due to lipid accumulation, endoplasmic reticulum (ER) stress,

mitochondrial dysfunction and increased ovarian cell apoptosis, these mice displayed anovulation

and reduced in vivo fertilization rates (Wu et al. 2010), as well as abnormal embryo development

(Minge et al. 2008). We have recently demonstrated the establishment of leptin resistance in the

ovaries of mice treated with HFD (Wołodko et al. 2020) was mostly mediated by suppressor of

cytokine signalling 3 (SOCS3). Hence, changes in local leptin signalling were shown to contribute to

the pathophysiology of ovarian failure in obese females (Wołodko et al. 2021).

The inflammasome is a large intracellular protein complex that contains a cytosolic pattern

recognition receptor. Among NOD-like receptors (NLR), the NLR protein 3 (NLRP3) inflammasome

72 has been best characterised as a complex of proteins responsible for controlling the activity of two

73 proinflammatory cytokines interleukin (IL)-1 $\beta$ and IL-18 (Davis, Wen, and Ting 2011; De Nardo and

74 Latz 2011; Martinon, Burns, and Tschopp 2002). Activation of the pattern recognition receptor

75 NLRP3 can be accomplished through two major signals: (i) priming signal, induced by the toll-like

76 receptor (TLR)/nuclear factor (NF)- $\kappa$ B pathway; and (ii) pathogen-associated molecular patterns

77 (PAMPs) and damage-associated molecular patterns (DAMPs) leading to assembly of inflammasome 
(Lamkanfi and Dixit 2014; Martinon, Burns, and Tschopp 2002). Both mechanisms lead to the

recruitment of the adapter apoptosis-associated speck-like protein containing a C-terminal caspase recruitment domain (ASC), resulting in the activation of pro-caspase-1 (CASP1) and cleavage into

81 the active form (Davis, Wen, and Ting 2011). The formation and activation of the inflammasome is possible through ASC, which links NLRP3 to CASP1 by means of its pyrin and caspase recruitment domain motifs (Martinon et al. 2006). Finally, activated CASP1 is known to process the maturation of IL-1 $\beta$ and IL-18 into active cytokines (Lamkanfi 2011). Importantly, obesity and insulin resistance (IR) have been associated with inflammation and subsequent activation of NLRP3 inflammasome (Traba and Sack 2017). The onset of inflammasome activation was also shown to be mediated by factors like glucose, ceramide, uric acid, or lipopolysaccharide (LPS) (Stienstra et al. 2012; Traba and Sack 2017). Furthermore, secondary signals could also come from extracellular ATP inducing K+ efflux; DAMPs/PAMPS leading to reactive oxygen species (ROS) production (Shao et al. 2015; activation through both signals (Wen et al. 2011), as increased levels of FFAs are a general feature of obesity, IR or type-2 diabetes (Boden 2002; Krebs and Roden 2005). More recently, a link has been also established between NLRP3 inflammasome activation and levels of leptin signalling in various cellular contexts (Fu et al. 2017), corroborating the proinflammatory role of leptin (Cauble et al. 2018).

A recent report has shown the presence of NLRP3 inflammasome components at ovarian level during follicular development in mice, suggesting its involvement in ovulation (Z. Zhang, Wang, and Zhang 2019). Most importantly, NLRP3 was also suggested to be involved in the pathophysiology of polycystic ovary syndrome (PCOS) (Rostamtabar et al. 2020). Therefore, we

100 presently hypothesise the regulation of NLRP3 in the ovary of obese mice is mediated by leptin 101 signalling. We firstly confirmed NLRP3 inflammasome expression profile changed in the ovaries of 
102 cyclic mice. Subsequently, we also confirmed NLRP3 inflammasome components were differently

103 expressed in the ovaries of 4 and 16 weeks (wk) diet induced obese (DIO) mice. Furthermore, using a

104 mouse model of pharmacological hyperleptinemia (LEPT) and a genetic obese mouse which lacks

105 leptin $(o b / o b)$ we demonstrated the association between levels of leptin signalling and NLRP3

106 inflammasome activation in the ovary of obese mice. Moreover, we analysed the transcriptome of

107 cumulus cells (CCs), the somatic companions of the oocyte, and concluded once more that leptin

108 treatment-upregulated genes associated with NLRP3 inflammasome. Finally, we studied the NLRP3

109 inflammasome expression in the liver of DIO, LEPT and $o b / o b$ mice and despite observing a

110 different temporal signature in DIO, with regard to the ovary, we also found a consistent

111 downregulation in NLRP3 inflammasome activity in $o b / o b$, which are obese and lack leptin.

\section{Materials \& Methods}

114 Female B6 mice (8 wk old) and B6.Cg-Lepob/J (ob/ob) were housed in the Animal Facility of

115 Institute of Animal Reproduction and Food Research, Polish Academy of Sciences in Olsztyn.

116 Breeding pairs were purchased from Jackson Laboratories (Bar Harbor, ME). Mice were housed with

117 free access to food and water for the duration of the study (humidity $50 \pm 10 \% ; 23^{\circ} \mathrm{C} ; 12 \mathrm{~L}: 12 \mathrm{D}$ cycle).

118 All procedures were approved by the Local Animal Care and Use Committee for University of

119 Warmia and Mazury, Olsztyn. Guidelines for animal experiments followed EU Directive

120 2010/63/EU. Throughout the whole experiments, mice were monitored for any sings of welfare or

121 disease. At 21 days of age female progeny were weaned and housed in groups of 3-5 in plastic cages

122 with fresh sawdust bedding. By 8 wk of age, one group of B6 mice was subjected to hormonal

123 protocol, while the other group was segregated into two different dietary protocols matched for

124 similar body weight. In DIO model ( $\mathrm{n}=10 /$ group) mice were placed on standard CD (Picolab Rodent 
125 diet 20, \#5053) with $13 \%$ of calories coming from fat, or on HFD with $59 \%$ of calories coming from

126 fat (AIN-76A with 33\% hydrogenated coconut oil; LabDiet) for 4 or 16 wk. Hyperleptinemia model

127 ( $\mathrm{n}=8$ /group) was utilized to mimic high level of leptin through its intraperitoneal injections twice a

128 day at total dosage $100 \mu \mathrm{g} /$ day (injected at 09:00 and 21:00), while the control group received saline

129 injections(Recombinant Mouse Leptin, GFM26, Cell Guidance Systems). Regarding $o b / o b$ model

130 (n=6/group), mice were kept on CD until 12 wk of age.

\subsection{Induction of oestrus and dioestrus stages}

132 The oestrous cycle was monitored studying vaginal cytology. Cells collected via saline lavage

133 were placed on glass slide and stained with Diff Quik® kit (Medion Diagnostics AG, Switzerland,

134 DQ-ST). Oestrus was characterised by cornified epithelium cells; metoestrus by both cornified cells

135 and leukocytes; dioestrus by predominant leukocytes; and pro-oestrus by nucleated cells, as

136 previously described (Kyrönlahti et al. 2011).

137 Group of female B6 mice (8 wk old) was injected in oestrus stage with eCG (G4877, 5IU, Sigma

138 Aldrich, Saint Louis, Missouri, USA) followed after 48 h by hCG (Chorulon, 5IU, MSD Animal

139 Health, Boxmeer, Netherlands) and tissues collected 18-20 h later in E. The second group of mice

140 were injected with hCG and tissues were collected 16-18 h later in D. To reduce variation between

141 groups ovaries from females from the remaining experiments were collected in dioestrus stage.

143 Protein expression in mouse ovary and liver was assessed by Western blotting. Ovaries and livers

144 were homogenized with RIPA buffer (R0278; Sigma) containing protease inhibitors

145 (phenylmethylsulfonyl fluoride, PMSF and Protease Inhibitor Cocktail, P8340; Sigma-Aldrich, St.

146 Louis, MO, US) and phosphatase inhibitors (Pierce Phosphatase Inhibitor Mini Tablets 88667; 
147 Thermo Fisher Scientific) and incubated on ice for $1 \mathrm{~h}$ while vortexing in the meantime. After

148 centrifugation $\left(20000 \mathrm{~g}, 15 \mathrm{~min}, 4^{\circ} \mathrm{C}\right)$ the supernatants were collected and protein concentration was

149 determined with the Smith (Smith 1985) copper/bicinchoninic assay (Copper (II) Sulfate, C2284;

150 Sigma and Bicinchoninic Acid Solution, B9643, Sigma). Samples were run (40 $\mu$ g of protein) on 10-

$151 \quad 18 \%$ polyacrylamide gels. Immunoblotting was performed using the following primary antibodies

152 NLRP3 (AG-20B-0014-C100; Adipogen), CASP1 (ab108362; Abcam), IL-18 (ab71495; Abcam), $\beta$ -

153 actin (A2228; Sigma), glyceraldehyde 3-phosphate dehydrogenase (GAPDH, ab9485; Abcam) and

154 then transferred to nitrocellulose (10600009; GE Healthcare Life Science) or polyvinylidene fluoride

155 (PVDF) membrane (IPVH00010; Merck Millipore). The membranes were blocked in phosphatase

156 buffered saline (PBS) solution containing 3\% powdered milk for $1 \mathrm{~h}$. Primary antibodies were used at

157 1:1 000 (NLRP3, CASP1) and 1:250 (IL-18) dilution and incubated overnight at $4^{\circ} \mathrm{C}$. The following

158 day, proteins were detected by incubating the membranes with a polyclonal anti-mouse horseradish

159 peroxidase (HRP)-conjugated secondary (1:10 000, 31430; Thermo Fisher Scientific), polyclonal

160 anti-rabbit HRP-conjugated secondary (1:20 000, 31460; Thermo Fisher Scientific), polyclonal anti-

161 mouse alkaline phosphatase-conjugated secondary (1:10 000, 31321; Thermo Fisher Scientific) and

162 polyclonal anti-rabbit alkaline phosphatase-conjugated secondary (1:10 000, A3687, Sigma)

163 antibodies, for $1,5 \mathrm{~h}$ in chemiluminescence method or $2,5 \mathrm{~h}$ in colorimetric method at room

164 temperature (RT). All antibodies specifications are summarised in Table 1. Immunocomplexes were

165 visualized subsequently using chemiluminescence detection reagent (SuperSignal West Femto kit,

34095; Thermo Fisher Scientific) or chromogenic substrate NBT/BCIP diluted 1:50 (11681451001;

167 Roche) in alkaline phosphate buffer. Band density for each of the target protein was normalised

168 against $\beta$-actin for NLRP3 and IL-18, while GAPDH was used for CASP1 as a reference protein.

169 Finally, bands were quantified using the ChemiDoc or VersaDoc MP 4000 imaging system (Bio-

170 Rad). Quantitative measurements of blot intensity were performed using ImageLab software. 
Total RNA was extracted from whole ovary and $10 \mathrm{mg}$ of liver, using TRI reagent (T9424;

173 Sigma Aldrich) following the manufacturer's instructions. RNA samples were stored at $-80^{\circ} \mathrm{C}$.

174 Concentration and quality of RNA was determined spectrophotometrically and the ratio of

175 absorbance at 260 and $280\left(\mathrm{~A}_{260 / 280}\right)$ was analysed confirming good RNA quality. Subsequently, 2

$176 \square \mu \mathrm{g}$ of RNA was reverse transcribed into cDNA using Maxima First Strand cDNA Synthesis Kit for

177 RT-qPCR (K1642; ThermoFisher Scientific) (Galvão et al. 2012).

Real-time PCR assays were performed in a 7900 Real-time System (Applied Biosystems), using a

180 default thermocycler program for all genes: a 10 min preincubation at $95^{\circ} \mathrm{C}$ was followed by 45

181 cycles of $15 \mathrm{sec}$ at $95^{\circ} \mathrm{C}$ and $1 \mathrm{~min}$ at $60^{\circ} \mathrm{C}$. A further dissociation step $\left(15 \mathrm{sec}\right.$ at $95^{\circ} \mathrm{C}, 15 \mathrm{sec}$ at

$18260^{\circ} \mathrm{C}$, and $15 \mathrm{sec}$ at $95^{\circ} \mathrm{C}$ ) ensured the presence of a single product. Ribosomal protein L37 (Rpl37)

183 was chosen as a house keeping gene and quantified in each real-time assay together with target gene.

184 Based on gene sequences in GenBank (National Center for Biotechnology Information), the primers

185 for Nlrp3, Casp1, Il-1 $\beta, I l-18, A s c, I l-10$, Tnf, which sequences are presented in Table 2, were

186 designed using Primer Express 3.0 software (Applied Biosystems). All reactions were carried out in

187 duplicates in 384-well plate (4309849; Applied Biosystems) in $12 \mu$ of total solution volume

188 (Galvão et al. 2014). The data were analysed using the real-time PCR Miner algorithm (S. Zhao and

189 Fernald 2005).

191 The concentrations of IL-1 $\beta$ in tissue extracts of ovaries and livers were determined using an IL-1

192 beta Pro-form Mouse Uncoated ELISA kit (88-8014-22; Thermo Fisher Scientific) following 

and interassay coefficient variation (CV ) was $7.27 \%$.

197 Software, Inc.; La Jolla, CA, USA). Paired t test was employed to compare the changes of protein

expression in mouse livers and ovaries. Comparisons of gene expression were performed using

199 Wilcoxon matched pairs test. Results are presented as mean with standard deviation. Differences

200 between the means for all tests were considered statistically significant if $\mathrm{p}<0.05$.

Methods followed the previously described (Wołodko et al. 2020). The GEO accession

number for the dataset Sequencing is under submission.

\section{Results}

We first sought to characterise the expression of NLRP3-induced inflammasome components

described (Hasegawa et al. 2016). Ovaries were collected in oestrus (E) and dioestrus (D) stage and

211 further processed for mRNA or protein expression analysis, respectively. Real-time PCR analysis

212 ( $\mathrm{n}=7 /$ group) revealed increased levels of Caspl, $I l-1 \beta$ and $I l-18 \mathrm{mRNA}$ in D stage (Figure 1B,

$213 \mathrm{p}<0.05)$. Moreover, Western blotting revealed increased NLRP3 protein expression in D (Figure 1C,

$214 \mathrm{p}<0.05)$, as well as the pro-peptide ( $\mathrm{p} 24)$ and mature form (p18) of IL-18 (Figure 1F, G; $\mathrm{p}<0.01)$. 
215 Regarding CASP1, the long form (p45) was decreased in D (Figure 1D; $\mathrm{p}<0.05$ ), but no significant

216 changes were observed for the active CASP1 (p20) (Figure 1E). These results suggest the activation

217 of NLRP3 inflammasome in D stage, through upregulation of NLRP3 and its downstream mediator

218 IL-18. Next, we characterised the cellular distribution of NLRP3 protein in the ovaries collected from

219 mice in D, using immunohistochemistry (IHC) and immunofluorescence (IF). We confirmed that

220 NLRP3 protein was globally distributed in the ovary (Figure 1I). On the other hand, a closer

221 observation with IHC revealed staining in granulosa cells (GC) and theca cells (TC), as well as

222 oocytes, in all developmental stages of follicles in the ovary (Figure 1K-M). Negative controls

223 stained with secondary antibodies did not reveal any brown staining (Figure 1H, J). The specificity

224 of our IHC staining was corroborated by IF, in which a clear brown staining was observed in GC, TC

225 and oocytes (Figure 10-U). Negative control stained with rabbit immunoglobulin type G (IgG)

226 confirmed no staining (Figure 1N). Our results once more corroborate the findings of Zhang and co-

227 workers who not only observed the presence of NLRP3 protein in GC, TC and oocytes by IHC, but

228 also confirmed the upregulation of NLRP3 in the ovaries of eCG treated mice (Z. Zhang, Wang, and

229 Zhang 2019). Therefore, in subsequent experiments, collections were consistently performed in D.

\subsection{Time-course activation of NLRP3-induced inflammasome in the ovary of DIO mice}

In the following experiment, we tested the effect of short (4 wk) versus long term (16 wk)

used the DIO protocol previously validated, in which female mice were fed chow diet (CD) or HFD

for 4 or $16 \mathrm{wk}$ ( $\mathrm{n}=8 /$ group) (Wołodko et al. 2020). After the DIO protocol, we recorded the average

body weight (BW) of 19.7 gram (g) in 4 wk CD group and $24.8 \mathrm{~g}$ in 4 wk HFD group, whereas the

23616 wk CD presented on average BW of $22.6 \mathrm{~g}$ and 16 wk HFD $37.6 \mathrm{~g} \mathrm{BW}$ (Table 3). After

237 collection, ovaries were processed for mRNA and protein expression analysis. Real-time PCR

238 analysis $(\mathrm{n}=6-8)$ revealed increased mRNA of Nlrp3 after 4 wk HFD (Figure 2B, p=0.06), whereas 
Il-1 $\beta$ levels were increased after both 4 wk and 16 wk of HFD (Figure 2B, p<0.05). Regarding

240 Western blotting analysis $(\mathrm{n}=8)$, we found the expression of NLRP3, CASP1 p45 and pro-IL-18 p24

241 were increased in 4 wk HFD group, compared to control group (Figure 2C, D, and F, p<0.05,

242 respectively). However, opposite pattern was observed in 16 wk HFD, with downregulation of

243 NLRP3 expression, the mature form of CASP1 p20 and both forms of IL-18 (p24 and p18) (Figure 2

244 C, E, F and $\mathbf{G}, \mathrm{p}<0.05)$. Finally, we also confirmed IL-1 $\beta$ protein level was upregulated in 16 wk

245 HFD after measurement by enzyme linked immunosorbent assay (ELISA) (n=6) (Figure 2H,

$246 \mathrm{p}=0.082)$. Therefore, we presently confirmed that NLRP3, the pro-proteins IL-18 (p18, p24) and

247 CASP1 (p45) despite being upregulated after 4 wk HFD treatment, after 16 wk HFD treatment a

248 consistent downregulation of NLRP3 inflammasome, particularly NLRP3, CASP1 (p20) and both

249 forms of IL-18, was seen. As a result, increased IL-1 $\beta$ protein after 16 wk HFD should be promoted

250 independently from the NLRP3 inflammasome pathway (Lukens et al. 2014; Ranson et al. 2018).

4.3 Leptin signalling in the ovary drives activation of NLRP3 inflammasome during obesity

progression

After temporally characterising the expression profile of NLRP3-induced inflammasome

254 components in the ovary of DIO mice, we further interrogated whether activation of the NLRP3

255 inflammasome was regulated by leptin signalling. Indeed, leptin was previously shown to modulate

256 NLRP3 expression in vitro (Fu et al. 2017). Furthermore, the expression signature of NLRP3

257 inflammasome components in the ovaries of DIO mice overlapped both tyrosine 985 of leptin 258 receptor (Tyr985ObRb) and Janus kinase 2 (JAK2) phosphorylation profile, with the increase at 4 wk

259 HFD treatment being followed by inhibition at 16 wk HFD and concomitant establishment of leptin

260 resistance (Wołodko et al. 2020). Therefore, we analysed the levels of NLRP3 inflammasome

261 components in the ovaries of a previously validated mouse model of pharmacological

262 hyperleptinemia, which presented increased systemic levels of leptin and increased leptin signalling 
263 in the ovary without obesity (Wołodko et al. 2020), and a genetically obese mouse B6.Cg-Lepob/J

$264(o b / o b)$, characterised by extreme obesity without leptin. In the pharmacological hyperleptinemic

265 model, ten female B6 8 wk old mice, were treated with leptin intraperitoneally, twice a day for 16

266 days (16 L), whereas controls were administered saline (16 C) (Wołodko et al. 2020). Moreover, ten

267 female $o b / o b$ control (+/?) and ten females homozygous mutant (-/-), 8 wk old were kept on CD for 4

268 wk (Figure 3A). Ovaries from all groups were collected and processed for mRNA and protein

269 expression analysis. Real-time PCR analysis ( $\mathrm{n}=6-8 /$ group) revealed an increase in Nlrp3 and Casp1

270 in $16 \mathrm{~L}$, but decrease in $o b / o b-/-$ mice (Figure 3B, p<0.05). Furthermore, mRNA of $I l-1 \beta$ was

271 upregulated in $16 \mathrm{~L}$ (Figure 3B, $\mathrm{p}<0.05$ ). Finally, the mRNA of $I l-18$ was significantly

272 downregulated in $o b / o b$-/- group (Figure 3B, p<0.05). With regard to protein expression, we found

273 the 16 L group presented increased levels of NLRP3 (Figure 3C, p<0.05), whereas the opposite

274 pattern was observed in $o b / o b$-/- mice, comparing to control groups (Figure 3C, $\mathrm{p}<0.05$ ).

275 Accordingly, both pro-peptides CASP1 (p45) and CASP1 (p20) showed increased levels in 16 L

276 (Figure 3D, E; $\mathrm{p}=0.07$ and $\mathrm{p}<0.05$, respectively), nonetheless, no significant changes were found in

277 the $o b / o b$ model. Importantly, IL-1 $\beta$ protein measured by ELISA was increased in 16 L, but

278 decreased in $o b / o b-/-($ Figure 3F, p <0.05). In this experiment we revealed the functional link

279 between leptin signalling and NLRP3 inflammasome components regulation in the ovary, with leptin

280 treatment inducing the activation of NLRP3 and CASP1 with subsequent secretion of IL-1 $\beta$.

281 Furthermore, the absence of NLRP3 inflammasome activation in the ovary of ob/ob -/- confirms the

282 preponderant role active leptin signalling exerts on NLRP3 inflammasome activation in the ovary.

In this experiment we examined whether the association previously observed between leptin

286 signalling and NLRP3 inflammasome activation found in whole ovaries holds true at the cellular 
level, particularly for the somatic companions of the female gamete, the CCs. Indeed, the ovary is a

very heterogeneous organ, with follicles in different developmental stages, and different somatic cells supporting oocyte development (Chang, Qiao, and Leung 2017). Therefore, we reanalysed our RNA sequencing (RNA-seq) datasets from CCs from the 4 wk HFD, 16 wk HFD and 16 L groups

(Wołodko et al. 2020). Briefly, we collected approximately 50 CCs per animal, after superovulation,

al. 2020). We started confirming the expression level of leptin and NLRP3 pathway components for

$16 \mathrm{~L}$ and 4 wk HFD. Despite no changes in Nlrp3 in CCs after 4 wk HFD, the gene was upregulated

in $16 \mathrm{~L}$ (Figure 4B). Certainly, the low coverage of the samples (an average of 5.5 million reads) and

the weak expression level of Nlrp3 in CCs may account for the lack of changes in 4 wk HFD.

Nonetheless, the consistent upregulation of various components of the NLRP3 inflammasome, like

Nlrp3 itself, or Il-18, Caspl, Il-1 $\beta$ and Asc in $16 \mathrm{~L}$, is suggestive of the stimulatory effect of leptin on

the expression of NLRP3 inflammasome genes also in CCs (Figure 4B). As previously shown,

DESeq analysis revealed 997 differentially expressed genes (DEGs) in 4 wk HFD and 2026 DEGs in

16 L (Wołodko et al. 2020), in comparison to their control groups ( $\mathrm{p}<0.05$; Wołodko et al. 2020). In

the present analysis, we overlapped the DEGs from 4 wk HFD and 16 L and identified seven genes

either up- or downregulated in both conditions (Figure 4C). Subsequently, we integrated these 14

304 DEGs with the main components of NLRP3 and leptin signalling pathways (Wołodko et al. 2020)

based on the correlation between their expression levels ( $>>0.90)$, obtaining five clusters, with one of

$1 \beta$, known as an important axis involved in the mediation of immune response (Chaves de Souza et 
312 (Yamaguchi et al. 1999). Indeed, metabolic performance in the preovulatory follicle is tightly

313 regulated and involves the crosstalk between GC and oocyte (Wołodko et al. 2021). Also, the ER

314 stress is a common feature observed in the ovaries of obese mothers (Robker, Wu, and Yang 2011)

315 (Figure 4D). Finally, gene ontology analysis for the presented network revealed three main events, as

316 negative regulation of glucose transport, positive regulation of cytokine biosynthesis and response to

317 ATP (Figure 4E, p<0.05). Those certainly are key processes for oocyte maturation, as glucose

318 metabolism in GC provides energy supplies for oocyte maturation (Wołodko et al. 2021).

319 Furthermore, energy production through lipid oxidation and ATP production, is also fundamental for

320 oocyte maturation (Wołodko et al. 2021). Finally, we plotted a subset of genes known to directly

321 activate the NLRP3 inflammasome signalling pathway (Weber et al. 2020), particularly regarding the

322 regulation of glutathione, major mediator of NLRP3 signalling (Hughes et al. 2019), as well as other

323 genes involved in the pathway regulation (Barlan et al. 2011; Billon et al. 2019; Guglielmo et al.

324 2017; Y. He et al. 2016; Hughes et al. 2019; Hughes and O’Neill 2018; Iyer et al. 2013 ; Jo et al.

325 2016; Kim et al. 2015; Li et al. 2016; Martine et al. 2019; Mitoma et al. 2013; Palazón-Riquelme et

326 al. 2018; Shuvarikov et al. 2018; X. Wang et al. 2014; Wolf et al. 2016; T. Zhang et al. 2021; Zhou et

327 al. 2010), and confirmed the similarities between $16 \mathrm{~L}$ and 4 wk HFD for those gene lists, in

328 opposition to 16 wk HFD (Figure 4F). Thus, as presently shown, systemic administration of leptin

329 activated genes from the NLRP3 inflammasome pathway in CCs, corroborating once more the

330 functional link between leptin signalling and NLRP3 inflammasome activation in CCs of DIO mice.

\subsection{Time-course activation of NLRP3-induced inflammasome in liver of DIO mice}

333 Therefore, in the last experiment was asked to what extent mounting inflammatory response through

334 NLRP3 inflammasome activation in the ovaries of DIO mice precede other metabolic organs like the

335 liver. We analysed the expression profile of NLRP3 inflammasome genes in the liver of DIO mice, 
besides testing once more the functional link between leptin signalling and activation of NLRP3

337 inflammasome at hepatic level, using pharmacological hyperleptinemic and $o b / o b$ mouse models.

338 Liver samples were collected from DIO, leptin treated and $o b / o b$ female mice, for mRNA

339 transcription and protein expression analysis (Figure 5A). Real-time PCR analysis (n=5-7/group)

340 showed no significant changes in expression of all inflammasome components, except for the

341 increase of Nlrp3 and $I l-1 \beta$ mRNA in 16 wk HFD, but downregulation of Nlrp3 in ob/ob-/- (Figure

3425 5B, $\mathrm{p}<0.05)$. Furthermore, protein analysis determined by Western blotting (n=4-8/group) showed an

343 increase in protein levels of NLRP3, CASP1 (p20), and IL-18 (p18) after 16 wk HFD treatment,

344 comparing to control (Figure 5C, $\mathbf{E}$ and $\mathbf{G}, \mathrm{p}=0.07, \mathrm{p}<0.05$ ). Regarding the pro-peptide of CASP1

345 (p45), its protein was upregulated in $16 \mathrm{~L}$, but downregulated in $o b / o b-/-$, comparing to controls

346 (Figure 5D, p <0.05 and p<0.01, respectively). Finally, CASP1 ( $\mathrm{p} 20)$ and IL-18 (p18) proteins were

347 decreased in $o b / o b-/-$ (Figure 5E, G, p $<0.05$ and $\mathrm{p}=0.08$, respectively). No significant changes were

348 observed for pro-IL-18 (p24). The present results on our analysis in the liver indicate a site dependent

349 NLRP3 inflammasome regulation throughout obesity, since overexpression of NLRP3, CASP1 (p20)

350 and IL-18 (p18) took place only at $16 \mathrm{wk}$ of DIO. Differences in NLRP3 inflammasome profile

351 between liver and ovary certainly relay on the intrinsic immunological complexity the liver presents.

352 The liver, in opposition to the ovary, is constantly exposed to proinflammatory mediators, having

353 developed the ability to tightly control inflammation (Robinson, Harmon, and O'Farrelly 2016).

354 Another important observation was the downregulation of NLRP3 and CASP1 (p20) in livers from

355 ob/ob -/- mice. Other studies corroborated these observations (Negrin et al. 2014), and despite all

356 intricacies of NLRP3 inflammasome regulation, leptin seems to directly modulate NLRP3

357 inflammasome activation at hepatic level. Hence, we confirmed the latency of NLRP3 inflammasome

358 activation in the liver of DIO female mice, which showed signs of upregulation only after 16 wk

359 HFD treatment. Furthermore, we have confirmed the functional link between leptin and NLRP3

360 inflammasome activation in the liver. 


\section{Discussion}

363 in the ovaries of DIO mice. Maternal obesity has been largely associated with increased ovarian

364 inflammation (J. Nteeba et al. 2013; Jackson Nteeba, Ganesan, and Keating 2014; Robker, Wu, and

365 Yang 2011; Ruebel et al. 2017; Snider and Wood 2019), being a better knowledge of its pathogenesis

366 of undeniable value for our understanding of ovarian failure and infertility during obesity. We firstly

367 confirmed the effects of cyclicity on NLRP3 inflammasome activation in the ovaries of lean mice,

368 observing the upregulation of NLRP3 inflammasome components in D. Subsequently, we temporally

369 characterised the expression profile of NLRP3 inflammasome components in the ovary, throughout

370 obesity progression. Indeed, the rapid upregulation of NLRP3 protein in early obesity (after 4 wk

371 HFD treatment), was followed by a consistent downregulation of NLRP3 inflammasome

372 components, as NLRP3 and CASP1, in late obesity (after 16 wk HFD). Importantly, using either a

373 pharmacological hyperleptinemic and a genetic obese ob/ob mouse, we not only evidenced the

374 functional link between levels of leptin signalling and NLRP3 activation in whole ovaries, but also

375 the role of leptin on Nlrp3, Il-18 and $I l-1 \beta$ gene expression upregulation in CCs from ovulated

376 follicles. Finally, after analysing the NLRP3 inflammasome expression pattern in the liver, we

377 confirmed NLRP3 and CASP1 overexpression took place exclusively after 16 wk HFD treatment,

378 suggesting a delayed activation of NLRP3 inflammasome activation in comparison with the ovary.

379 Hence, these results suggest a greater vulnerability of the ovaries in general, and the gamete in

380 particular, to the energetic surplus females face under obesogenic conditions.

A recent study by Zhang and colleagues evidenced for the first time NLRP3 expression in

382 various cellular components like GC, TC and oocytes of mouse ovaries (Z. Zhang, Wang, and Zhang

383 2019). We presently confirmed not only the similar pattern of cellular expression for NLRP3, but

384 also the upregulation of NLRP3 inflammasome components during D. These findings corroborate 
previous results suggesting the involvement of NLRP3 in inflammation during ovulation in mice (Z. starts getting noticed not only under physiological context (Z. Zhang, Wang, and Zhang 2019), but also as an important mediator of ovarian pathology during ageing (Navarro-Pando et al. 2021). Certainly, our hypothesis of NLRP3 inflammasome involvement in inflammatory response in the ovary of obese mothers seems to be supported also by earlier reports showing NLRP3 inflammasome activation during development and treatment of PCOS (Guo et al. 2020; F. Wang et al. 2017). activation in the ovaries of 4 wk HFD treatment are in line with previous reports showing the

as well as increased mRNA of Tnf (data not shown), after 4 wk HFD underscoring the mounting

IL-1 $\beta$ at 16 wk HFD confirm the existence of alternative pathways to NLRP3 inflammasome, 
2020). In early obesity, inflammatory cues in CCs were mediated by cellular response to stress

410 through upregulation of genes like DEAD-box helicase 5 (Ddx5), hypoxia inducible factor 1 subunit

411 alpha (Hifla), ADAM metallopeptidase domain 9 (Adam9). Indeed, mediators of stress response as

412 ROS are known to prime the NLRP3 inflammasome (Gurung et al. 2014). Subsequently, in late

413 obesity, we saw the overexpression of genes involved in anatomical structural morphogenesis, as $C$ -

414 C motif chemokine ligand 7 (Ccl7), an important chemoattractant of leukocytes (Menten et al. 1999),

415 and also known to interact with matrix metalloproteinases (MMPs) (Liu et al. 2018), or complement

$416 \mathrm{C} 3 \mathrm{a}$ receptor 1 ( C3arl), a complement component known to mediate neutrophil mobilisation

417 (Brennan et al. 2019) and lately described as a marker of PCOS progression (D. He et al. 2020).

418 Therefore, these data suggest important temporal dynamics on the regulation of the inflammatory

419 response in the ovary throughout obesity progression, with NLRP3 inflammasome playing a critical

420 role mostly in the initiation of inflammation in the ovaries in early obesity. Conversely, in late

421 obesity, immune mediated response in the ovary progresses to infiltration of immune cells and

422 structural reorganisation, independently from the activation of NLRP3 inflammasome.

423 Our study also sheds light on the important crosstalk between leptin signalling and

424 inflammasome NLRP3 activation in the ovary of DIO mice. As reviewed by Wani and co-workers,

425 numerous factors were shown to activate NLRP3 inflammasome during obesity, such as cellular

426 metabolites, carbohydrates or lipids (Wani et al. 2021). Nonetheless, leptin, a conserved

427 proinflammatory cytokine (Iikuni et al. 2008; La Cava 2017), was recently shown to upregulated

428 NLRP3 components in vitro (Fu et al. 2017). Thus, in order to test the hypothesis whether repression

429 of NLRP3 inflammasome activation in ovaries of 16 wk HFD mice was due to the establishment of

430 leptin resistance (Wołodko et al. 2020), we studied NLRP3 inflammasome activation in the ovaries

431 of pharmacological hyperleptinemic and ob/ob mice. Strikingly, we observed a consistent

432 upregulation of NLRP3 inflammasome genes and accumulation of IL-1 $\beta$ protein in ovaries of leptin 
433 treated mice, in opposition to $o b / o b$-/- mice which evidenced consistent downregulation of NLRP3

434 and IL-1 $\beta$ proteins. Furthermore, reduced levels of NLRP3 were also observed in $o b / o b$-/- mouse

435 peritoneal macrophages treated with LPS and nigericin in comparison to wild type mice (Yang et al.

436 2021), what certainly underlines the preponderant role of leptin on NLRP3 inflammasome regulation.

437 Therefore, our results invite us to suggest the activation of NLRP3 inflammasome in the ovary of

438 DIO mice is mediated by leptin signalling. In early obesity (4 wk HFD treatment) leptin actively

439 signals through receptor b (ObRb) in the ovary (Wołodko et al. 2020), with the overexpression of

440 NLRP3 inflammasome components; nonetheless, in late obesity (16 wk HFD treatment) after the

441 establishment of leptin resistance in the organ (Wołodko et al. 2020), expression of NLRP3

442 inflammasome is drastically repressed.

Next, we reanalysed our datasets on global gene expression in CCs collected from

444 pharmacological hyperleptinemic and DIO mice, in order to test the association between leptin

445 signalling and activation of NLRP3 inflammasome in the somatic companions of the oocyte.

446 Importantly, CCs are known as faithful indicators of intrafollicular environment (Wołodko et al.

4472021 ) and their transcriptome has been used to predict oocyte and embryo quality (Uyar, Torrealday,

448 and Seli 2013). Despite no changes in 4 wk HFD, we confirmed the overexpression of NLRP3

449 inflammasome genes in CCs from 16 L. Consequently, we interrogated whether DEGs overlapping

450 both $16 \mathrm{~L}$ and 4 wk HFD treatment could interacted with NLRP3 inflammasome genes. Indeed gene

451 ontology for associated genes revealed key terms for oocyte maturation, as regulation of glucose

452 transport, response to ATP and regulation of cytokine biosynthesis. Metabolic regulation in

453 preovulatory follicles appears to control major steps for maturation of female gamete, as meiosis

454 resumption, chromatin condensation and cytoplasm maturation (Wołodko et al. 2021). For instance,

455 glucose, which is mostly metabolised in CCs (Sanfins, Rodrigues, and Albertini 2018) was shown to

456 be key for oocyte competence (Wilding et al. 2009), as well as reduced ATP content in oocytes was 
457 linked to failure in fertilisation, arrested division and abnormal embryonic development (J. Zhao and

458 Li 2012). Furthermore, the aforementioned involvement of NLRP3 inflammasome in ovulation (Z.

459 Zhang, Wang, and Zhang 2019) can be considered amongst the regulation of the cytokine milieu

460 locally produced in CCs. Given leptin direct and indirect role in ovulation (Wołodko et al. 2021),

461 failure in leptin signalling and NLRP3 inflammasome activation in late obesity can account for

462 increased anovulatory rates in obese mothers (Hou et al. 2016; Wu et al. 2010). Finally, absence of

463 changes in $4 \mathrm{wk}$ HFD in NLRP3 inflammasome genes can be ascribed to low coverage of our

464 reduced-cell libraries and also low levels of gene expression. Indeed, the present RNA-seq protocol

465 used as little as 50 cells per mouse, which has limitations while analysing weakly expressed genes.

466 Collectively, our results indicate leptin and NLRP3 inflammasome crosstalk in CCs can interfere

467 with major steps regulating oocyte maturation and early embryo development.

In the last experiment we confirmed the liver, in sharp contrast to the ovary, activated NLRP3 inflammasome later in time during DIO protocol (after 16 wk HFD treatment) in mice. Temporal

differences in inflammatory response regulation between both organs certainly rely on contrasting exposition to exogenous pathogens. The liver is an organ constantly exposed to proinflammatory

Thus, the hepatic immune system is constantly in contact with altered metabolic activity and regular

response (Robinson, Harmon, and O'Farrelly 2016). On the contrary, the ovary is not only a highly immunogenic organ constantly secreting large amounts of cytokines and immune mediators (Piccinni et al. 2021), but also more prone to rapidly mounting proinflammatory response during obesity.

478 Indeed, the inability of the ovary to control inflammation and exacerbated cytokine production 479 certainly ascribes for the great vulnerability the female gamete presents to maternal obesity even at 
earlier stages. Thus, our results expose the increased ovarian vulnerability to maternal obesity, with a rapid mounting inflammation which affects the gamete and impairs fertilisation.

In summary, our work evidences the major role leptin signalling exerts on NLRP3 energetic surplus during maternal obesity.

\section{Conflict of Interest}

The authors have no conflict of interest to declare.

\section{Author Contributions}

491 MA did data acquisition, analysis and interpretation of the data, writing the manuscript; KW did data

492 acquisition and analysis and revised and edited the manuscript; JO did immunohistochemistry

493 staining; JCF conducted data analysis and interpretation of data, revising the manuscript; DM did

494 immunohistochemistry staining; GK revised and edited the manuscript; AG conceptualised and

495 designed the study, acquired the funding, participated in data acquisition, analysis and interpretation, 496 and wrote and edited the manuscript.

\section{Funding}

498 Work supported by grants from the Polish National Science Centre (No. 2016/23/B/NZ4/03737 and 499 2019/34/E/NZ4/00349) awarded to A. G.; A. G. was supported by Horizon 2020 Marie Curie

500 Individual Fellowship (MOBER, 2017-2019) and by the KNOW Consortium: "Healthy Animal 501 Safe Food” (Ministry of Sciences and Higher Education; Dec: 05-1/KNOW2/2015). 


\section{Acknowledgments}

503 We would like to thank Dr Leslie Paul Kozak and Dr Magdalena Jura for their support with the

504 validation and characterisation of the mouse obese phenotype; and Dr Krzysztof Witek for his 505 support with the imaging and confocal microscopy.

\section{Data Availability Statement}

507 The raw data supporting the conclusions of this article were made available within the publication

508 Wołodko et al 2020.

509

510

511

512

513

514

515

516

517

518 


\section{References}

Barlan, A. U., T. M. Griffin, K. A. McGuire, and C. M. Wiethoff. 2011. 'Adenovirus Membrane Penetration Activates the NLRP3 Inflammasome'. Journal of Virology 85 (1): 146-55. https://doi.org/10.1128/JVI.01265-10.

Billon, Cyrielle, Meghan H. Murray, Amer Avdagic, and Thomas P. Burris. 2019. 'ROR $\gamma$ Regulates the NLRP3 Inflammasome'. The Journal of Biological Chemistry 294 (1): 10-19. https://doi.org/10.1074/jbc.AC118.002127.

Boden, Guenther. 2002. 'Interaction between Free Fatty Acids and Glucose Metabolism'. Current Opinion in Clinical Nutrition and Metabolic Care 5 (5): 545-49. https://doi.org/10.1097/00075197-200209000-00014.

Brennan, Faith H., Trisha Jogia, Ellen R. Gillespie, Linda V. Blomster, Xaria X. Li, Bianca Nowlan, Gail M. Williams, et al. 2019. 'Complement Receptor C3aR1 Controls Neutrophil Mobilization Following Spinal Cord Injury through Physiological Antagonism of CXCR2'. JCI Insight 4 (9). https://doi.org/10.1172/jci.insight.98254.

Cauble, Reagan, S. Hamad, Ellen Herring, Callan Lichtenwalter, C. McGuire, and Sami Dridi. 2018. 'Leptin Activates NLRP3 Inflammasome-Associated with Type II Diabetes and Obesity'. Advances in Food Technology and Nutritional Sciences - Open Journal 4 (November): e1316. https://doi.org/10.17140/AFTNSOJ-4-e016.

Chang, Hsun-Ming, Jie Qiao, and Peter C.K. Leung. 2017. 'Oocyte-Somatic Cell Interactions in the Human Ovary-Novel Role of Bone Morphogenetic Proteins and Growth Differentiation Factors'. Human Reproduction $\quad$ Update 23 (1): 1-18. https://doi.org/10.1093/humupd/dmw039.

Chaves de Souza, João Antônio, Andressa Vilas Boas Nogueira, Pedro Paulo Chaves de Souza, Yeon Jung Kim, Caroline Silva Lobo, Guilherme José Pimentel Lopes de Oliveira, Joni Augusto Cirelli, Gustavo Pompermaier Garlet, and Carlos Rossa. 2013. 'SOCS3 Expression Correlates with Severity of Inflammation, Expression of Proinflammatory Cytokines, and Activation of STAT3 and P38 MAPK in LPS-Induced Inflammation In Vivo'. Mediators of Inflammation 2013. https://doi.org/10.1155/2013/650812.

Chu, Susan Y., Shin Y. Kim, Joseph Lau, Christopher H. Schmid, Patricia M. Dietz, William M. Callaghan, and Kathryn M. Curtis. 2007. 'Maternal Obesity and Risk of Stillbirth: A Metaanalysis'. American Journal of Obstetrics and Gynecology 197 (3): 223-28. https://doi.org/10.1016/j.ajog.2007.03.027.

Davis, Beckley K., Haitao Wen, and Jenny P.-Y. Ting. 2011. 'The Inflammasome NLRs in Immunity, Inflammation, and Associated Diseases'. Annual Review of Immunology 29: 70735. https://doi.org/10.1146/annurev-immunol-031210-101405.

De Nardo, Dominic, and Eicke Latz. 2011. 'NLRP3 Inflammasomes Link Inflammation and Metabolic Disease'. Trends in Immunology $32 \quad$ (8): 373-79. https://doi.org/10.1016/j.it.2011.05.004.

Donado, Carlos A., Anh B. Cao, Daimon P. Simmons, Ben A. Croker, Patrick J. Brennan, and Michael B. Brenner. 2020. 'A Two-Cell Model for IL-1 $\beta$ Release Mediated by DeathReceptor $\quad$ Signaling'. $\quad$ Cell $\quad$ Reports $31 \quad 307466$. https://doi.org/10.1016/j.celrep.2020.03.030. 
564

Fu, Sisi, Lei Liu, Lei Han, and Yiyun Yu. 2017. 'Leptin Promotes IL-18 Secretion by Activating the NLRP3 Inflammasome in RAW 264.7 Cells'. Molecular Medicine Reports 16 (6): 9770-76. https://doi.org/10.3892/mmr.2017.7797.

Galvão, António, Sofia Henriques, Daria Pestka, Karolina Lukasik, Dariusz Skarzynski, Luisa Maria Mateus, and Graça Maria Leitao Ferreira-Dias. 2012. 'Equine Luteal Function Regulation May Depend on the Interaction between Cytokines and Vascular Endothelial Growth Factor: An in Vitro Study'. Biology of Reproduction $86 \quad$ (6): 187. https://doi.org/10.1095/biolreprod.111.097147.

Galvão, António, Angela Tramontano, Maria Rosa Rebordão, Ana Amaral, Pedro Pinto Bravo, Anna Szóstek, Dariusz Skarzynski, Antonio Mollo, and Graça Ferreira-Dias. 2014. 'Opposing Roles of Leptin and Ghrelin in the Equine Corpus Luteum Regulation: An In Vitro Study'. Mediators of Inflammation 2014 (July): e682193. https://doi.org/10.1155/2014/682193.

Guglielmo, Andrew, Adham Sabra, Mostafa Elbery, Milena M. Cerveira, Fernanda Ghenov, Rajesh Sunasee, and Karina Ckless. 2017. 'A Mechanistic Insight into Curcumin Modulation of the IL-1 $\beta$ Secretion and NLRP3 S-Glutathionylation Induced by Needle-like Cationic Cellulose Nanocrystals in Myeloid Cells'. Chemico-Biological Interactions 274 (August): 1-12. https://doi.org/10.1016/j.cbi.2017.06.028.

Guo, Qing-Jun, Jing Shan, Yi-Feng Xu, Yan-Yan Hu, Cui-Lan Huo, Jing-Yun Song, Chao-Qun Wang, Hui Zhou, Chao-Qin Yu, and Qin Huang. 2020. 'Pioglitazone Metformin Complex Improves Polycystic Ovary Syndrome Comorbid Psychological Distress via Inhibiting NLRP3 Inflammasome Activation: A Prospective Clinical Study'. Mediators of Inflammation 2020: 3050487. https://doi.org/10.1155/2020/3050487.

Gurung, Prajwal, Paras K. Anand, R. K. Subbarao Malireddi, Lieselotte Vande Walle, Nina Van Opdenbosch, Christopher P. Dillon, Ricardo Weinlich, Douglas R. Green, Mohamed Lamkanfi, and Thirumala-Devi Kanneganti. 2014. 'FADD and Caspase-8 Mediate Priming and Activation of the Canonical and Noncanonical Nlrp3 Inflammasomes'. Journal of Immunology (Baltimore, $\quad$ Md.: $\quad$ 1950) $192 \quad$ (4): $1835-46$. https://doi.org/10.4049/jimmunol.1302839.

Hasegawa, Ayumi, Keiji Mochida, Hiroki Inoue, Yoshihiro Noda, Tamao Endo, Gen Watanabe, and Atsuo Ogura. 2016. 'High-Yield Superovulation in Adult Mice by Anti-Inhibin Serum Treatment Combined with Estrous Cycle Synchronization1'. Biology of Reproduction 94 (21, 1-8). https://doi.org/10.1095/biolreprod.115.134023.

He, Dongyun, Li Liu, Yang Wang, and Minjia Sheng. 2020. 'A Novel Genes Signature Associated with the Progression of Polycystic Ovary Syndrome'. Pathology Oncology Research: POR 26 (1): 575-82. https://doi.org/10.1007/s12253-019-00676-3.

He, Yuan, Hideki Hara, and Gabriel Núñez. 2016. 'Mechanism and Regulation of NLRP3 Inflammasome Activation'. Trends in Biochemical Sciences 41 (12): 1012-21. https://doi.org/10.1016/j.tibs.2016.09.002.

He, Yuan, Melody Y. Zeng, Dahai Yang, Benny Motro, and Gabriel Núñez. 2016. 'NEK7 Is an Essential Mediator of NLRP3 Activation Downstream of Potassium Efflux'. Nature 530 (7590): 354-57. https://doi.org/10.1038/nature16959.

Hotamisligil, Gökhan S., and Ebru Erbay. 2008. 'Nutrient Sensing and Inflammation in Metabolic Diseases'. Nature Reviews Immunology 8 (12): 923-34. https://doi.org/10.1038/nri2449.

Hou, Yan-Jun, Cheng-Cheng Zhu, Xing Duan, Hong-Lin Liu, Qiang Wang, and Shao-Chen Sun. 2016. 'Both Diet and Gene Mutation Induced Obesity Affect Oocyte Quality in Mice'. Scientific Reports 6 (1): 18858. https://doi.org/10.1038/srep18858.

Hughes, Mark M., Alexander Hooftman, Stefano Angiari, Padmaja Tummala, Zbigniew Zaslona, Marah C. Runtsch, Anne F. McGettrick, et al. 2019. 'Glutathione Transferase Omega-1 
612

613

614

615

616

617

618

619

620

621

622

623

624

625

626

627

628

629

630

631

632

633

634

635

636

637

638

639

640

641

642

643

644

645

646

647

648

649

650

651

652

653

654

655

656

657

658

659

Regulates NLRP3 Inflammasome Activation through NEK7 Deglutathionylation'. Cell Reports 29 (1): 151-161.e5. https://doi.org/10.1016/j.celrep.2019.08.072.

Hughes, Mark M., and Luke A. J. O'Neill. 2018. 'Metabolic Regulation of NLRP3'. Immunological Reviews 281 (1): 88-98. https://doi.org/10.1111/imr.12608.

Iikuni, Noriko, Queenie Lai Kwan Lam, Liwei Lu, Giuseppe Matarese, and Antonio La Cava. 2008. 'Leptin and Inflammation'. Current Immunology Reviews 4 (2): 70-79. https://doi.org/10.2174/157339508784325046.

Iyer, Shankar S., Qiong He, John R. Janczy, Eric I. Elliott, Zhenyu Zhong, Alicia K. Olivier, Jeffrey J. Sadler, et al. 2013. 'Mitochondrial Cardiolipin Is Required for Nlrp3 Inflammasome Activation'. Immunity 39 (2): 311-23. https://doi.org/10.1016/j.immuni.2013.08.001.

Jain, Aakanksha, Ricardo A. Irizarry-Caro, Margaret M. McDaniel, Amanpreet Singh Chawla, Kaitlin R. Carroll, Garrett R. Overcast, Naomi H. Philip, et al. 2020. 'T Cells Instruct Myeloid Cells to Produce Inflammasome-Independent IL-1 $\beta$ and Cause Autoimmunity'. Nature Immunology 21 (1): 65-74. https://doi.org/10.1038/s41590-019-0559-y.

Jo, Eun-Kyeong, Jin Kyung Kim, Dong-Min Shin, and Chihiro Sasakawa. 2016. 'Molecular Mechanisms Regulating NLRP3 Inflammasome Activation'. Cellular and Molecular Immunology 13 (2): 148-59. https://doi.org/10.1038/cmi.2015.95.

Jungheim, Emily S., Erica L. Schoeller, Kerri L. Marquard, Erica D. Louden, Jean E. Schaffer, and Kelle H. Moley. 2010. 'Diet-Induced Obesity Model: Abnormal Oocytes and Persistent Growth Abnormalities in the Offspring'. Endocrinology 151 (8): 4039-46. https://doi.org/10.1210/en.2010-0098.

Kim, So Ri, Yong Chul Lee, Hee Jung Kim, and Soon Ha Kim. 2015. 'Activation of NLRP3 Inflammasome Is Regulated by Mitochondrial ROS via PI3K-HIF-VEGF Pathway in Acute Lung Injury'. European Respiratory Journal $46 \quad$ (suppl 59). https://doi.org/10.1183/13993003.congress-2015.PA3026.

Krebs, M., and M. Roden. 2005. 'Molecular Mechanisms of Lipid-Induced Insulin Resistance in Muscle, Liver and Vasculature'. Diabetes, Obesity \& Metabolism 7 (6): 621-32. https://doi.org/10.1111/j.1463-1326.2004.00439.x.

Kyrönlahti, Antti, Melanie Vetter, Rosemarie Euler, Malgorzata Bielinska, Patrick Y. Jay, Mikko Anttonen, Markku Heikinheimo, and David B. Wilson. 2011. 'GATA4 Deficiency Impairs Ovarian Function in Adult Mice'. Biology of Reproduction 84 (5): 1033-44. https://doi.org/10.1095/biolreprod.110.086850.

La Cava, Antonio. 2017. 'Leptin in Inflammation and Autoimmunity'. Cytokine 98 (October): 51-58. https://doi.org/10.1016/j.cyto.2016.10.011.

Lamkanfi, Mohamed. 2011. 'Emerging Inflammasome Effector Mechanisms'. Nature Reviews Immunology 11 (3): 213-20. https://doi.org/10.1038/nri2936.

Lamkanfi, Mohamed, and Vishva M. Dixit. 2014. 'Mechanisms and Functions of Inflammasomes'. Cell 157 (5): 1013-22. https://doi.org/10.1016/j.cell.2014.04.007.

Li, Yi, Jia-Yi Zheng, Jian-Qun Liu, Jie Yang, Yang Liu, Chen Wang, Xiao-Nan Ma, Bao-Lin Liu, Gui-Zhong Xin, and Li-Fang Liu. 2016. 'Succinate/NLRP3 Inflammasome Induces Synovial Fibroblast Activation: Therapeutical Effects of Clematichinenoside AR on Arthritis'. Frontiers in Immunology 7 (December). https://doi.org/10.3389/fimmu.2016.00532.

Liu, Yangyang, Yadi Cai, Li Liu, Yudong Wu, and Xiangyang Xiong. 2018. 'Crucial Biological Functions of CCL7 in Cancer'. PeerJ 6: e4928. https://doi.org/10.7717/peerj.4928.

Lukens, John R., Jordan M. Gross, Christopher Calabrese, Yoichiro Iwakura, Mohamed Lamkanfi, Peter Vogel, and Thirumala-Devi Kanneganti. 2014. 'Critical Role for InflammasomeIndependent IL-1 $\beta$ Production in Osteomyelitis'. Proceedings of the National Academy of Sciences 111 (3): 1066-71. https://doi.org/10.1073/pnas.1318688111. 
660

661

662

663

664

665

666

667

668

669

670

671

672

673

674

675

676

677

678

679

680

681

682

683

684

685

686

687

688

689

690

691

692

693

694

695

696

697

698

699

700

701

702

703

704

705

706

707

Martine, Pierre, Angélique Chevriaux, Valentin Derangère, Lionel Apetoh, Carmen Garrido, François Ghiringhelli, and Cédric Rébé. 2019. 'HSP70 Is a Negative Regulator of NLRP3 Inflammasome Activation'. Cell Death \& Disease $10 \quad$ (4): 1-11. https://doi.org/10.1038/s41419-019-1491-7.

Martinon, Fabio, Kimberly Burns, and Jürg Tschopp. 2002. 'The Inflammasome: A Molecular Platform Triggering Activation of Inflammatory Caspases and Processing of ProIL-Beta'. Molecular Cell 10 (2): 417-26. https://doi.org/10.1016/s1097-2765(02)00599-3.

Martinon, Fabio, Virginie Pétrilli, Annick Mayor, Aubry Tardivel, and Jürg Tschopp. 2006. 'GoutAssociated Uric Acid Crystals Activate the NALP3 Inflammasome'. Nature 440 (7081): 23741. https://doi.org/10.1038/nature04516.

Menten, P., P. Proost, S. Struyf, E. Van Coillie, W. Put, J. P. Lenaerts, R. Conings, et al. 1999. 'Differential Induction of Monocyte Chemotactic Protein-3 in Mononuclear Leukocytes and Fibroblasts by Interferon-Alpha/Beta and Interferon-Gamma Reveals MCP-3 Heterogeneity'. European Journal of Immunology 29 (2): 678-85. https://doi.org/10.1002/(SICI)15214141(199902)29:02<678::AID-IMMU678>3.0.CO;2-J.

Minge, Cadence E., Brenton D. Bennett, Robert J. Norman, and Rebecca L. Robker. 2008. 'Peroxisome Proliferator-Activated Receptor-Gamma Agonist Rosiglitazone Reverses the Adverse Effects of Diet-Induced Obesity on Oocyte Quality'. Endocrinology 149 (5): 264656. https://doi.org/10.1210/en.2007-1570.

Mitoma, Hiroki, Shino Hanabuchi, Taeil Kim, Musheng Bao, Zhiqiang Zhang, Naoshi Sugimoto, and Yong-Jun Liu. 2013. 'The DEAH Box RNA Helicase DHX33 Senses Cytosolic RNA and Activates the NLRP3 Inflammasome'. Immunity 39 (1): 123-35. https://doi.org/10.1016/j.immuni.2013.07.001.

Navarro-Pando, José M., Elísabet Alcocer-Gómez, Beatriz Castejón-Vega, Elena Navarro-Villarán, Mónica Condés-Hervás, María Mundi-Roldan, Jordi Muntané, et al. 2021. 'Inhibition of the NLRP3 Inflammasome Prevents Ovarian Aging'. Science Advances 7 (1): eabc7409. https://doi.org/10.1126/sciadv.abc7409.

Negrin, Kimberly A., Rachel J. Roth Flach, Marina T. DiStefano, Anouch Matevossian, Randall H. Friedline, DaeYoung Jung, Jason K. Kim, and Michael P. Czech. 2014. 'IL-1 Signaling in Obesity-Induced Hepatic Lipogenesis and Steatosis'. PLOS ONE 9 (9): e107265. https://doi.org/10.1371/journal.pone.0107265.

Nigam, Sanjay K. 2018. 'The SLC22 Transporter Family: A Paradigm for the Impact of Drug Transporters on Metabolic Pathways, Signaling, and Disease'. Annual Review of Pharmacology and Toxicology 58 (January): 663-87. https://doi.org/10.1146/annurevpharmtox-010617-052713.

Nteeba, J., L. C. Ortinau, J. W. Perfield, and A. F. Keating. 2013. 'Diet-Induced Obesity Alters Immune Cell Infiltration and Expression of Inflammatory Cytokine Genes in Mouse Ovarian and Peri-Ovarian Adipose Depot Tissues'. Molecular Reproduction and Development 80 (11): 948-58. https://doi.org/10.1002/mrd.22231.

Nteeba, Jackson, Shanthi Ganesan, and Aileen F. Keating. 2014. 'Progressive Obesity Alters Ovarian Folliculogenesis with Impacts on Pro-Inflammatory and Steroidogenic Signaling in Female Mice1'. Biology of Reproduction $91 \quad$ (86, $1-11)$. https://doi.org/10.1095/biolreprod.114.121343.

Odegaard, Justin I., and Ajay Chawla. 2008. 'Mechanisms of Macrophage Activation in ObesityInduced Insulin Resistance'. Nature Clinical Practice. Endocrinology \& Metabolism 4 (11): 619-26. https://doi.org/10.1038/ncpendmet0976.

Palazón-Riquelme, Pablo, Jonathan D Worboys, Jack Green, Ana Valera, Fatima Martín-Sánchez, Carolina Pellegrini, David Brough, and Gloria López-Castejón. 2018. 'USP7 and USP47 
708

709

710

711

712

713

714

715

716

717

718

719

720

721

722

723

724

725

726

727

728

729

730

731

732

733

734

735

736

737

738

739

740

741

742

743

744

745

746

747

748

749

750

751

752

753

754

755

Deubiquitinases Regulate NLRP3 Inflammasome Activation'. EMBO Reports 19 (10): e44766. https://doi.org/10.15252/embr.201744766.

Penzias, Alan S. 2012. 'Recurrent IVF Failure: Other Factors'. Fertility and Sterility 97 (5): 103338. https://doi.org/10.1016/j.fertnstert.2012.03.017.

Piccinni, Marie-Pierre, Rossella Vicenti, Federica Logiodice, Raffaella Fabbri, Ornela Kullolli, Marco Pallecchi, Roberto Paradisi, et al. 2021. 'Description of the Follicular Fluid Cytokine and Hormone Profiles in Human Physiological Natural Cycles'. The Journal of Clinical Endocrinology \& Metabolism 106 (2): e721-38. https://doi.org/10.1210/clinem/dgaa880.

Pyrillou, Katerina, Laura C. Burzynski, and Murray C. H. Clarke. 2020. 'Alternative Pathways of IL1 Activation, and Its Role in Health and Disease'. Frontiers in Immunology 11. https://doi.org/10.3389/fimmu.2020.613170.

Ranson, Nicole, Mark Veldhuis, Brent Mitchell, Scott Fanning, Anthony L. Cook, Dale Kunde, and Rajaraman Eri. 2018. 'NLRP3-Dependent and -Independent Processing of Interleukin (IL)-1 $\beta$ in Active Ulcerative Colitis'. International Journal of Molecular Sciences 20 (1). https://doi.org/10.3390/ijms20010057.

Robinson, Mark W., Cathal Harmon, and Cliona O'Farrelly. 2016. 'Liver Immunology and Its Role in Inflammation and Homeostasis'. Cellular \& Molecular Immunology 13 (3): 267-76. https://doi.org/10.1038/cmi.2016.3.

Robker, Rebecca L. 2008. 'Evidence That Obesity Alters the Quality of Oocytes and Embryos'. Pathophysiology: The Official Journal of the International Society for Pathophysiology 15 (2): 115-21. https://doi.org/10.1016/j.pathophys.2008.04.004.

Robker, Rebecca L., Linda L. -Y. Wu, and Xing Yang. 2011. 'Inflammatory Pathways Linking Obesity and Ovarian Dysfunction'. Journal of Reproductive Immunology, XI International $\begin{array}{llllll}\text { Congress of } & \text { Reproductive } & \text { Immunology, } & 88 & \text { (2): }\end{array}$ https://doi.org/10.1016/j.jri.2011.01.008.

Rostamtabar, Maryam, Sedighe Esmaeilzadeh, Ahmad Karkhah, Mania Amiri, Abolfazl Rahmani, Fatemeh Bakouei, and Hamid Reza Nouri. 2020. 'Elevated Expression of IL-18 but Not IL-1 $\beta$ Gene Is Associated with NALP3 and AIM2 Inflammasome in Polycystic Ovary Syndrome'. Gene 731 (March): 144352. https://doi.org/10.1016/j.gene.2020.144352.

Ruebel, Meghan L., Matthew Cotter, Clark R. Sims, Dean M. Moutos, Thomas M. Badger, Mario A. Cleves, Kartik Shankar, and Aline Andres. 2017. 'Obesity Modulates Inflammation and Lipid Metabolism Oocyte Gene Expression: A Single-Cell Transcriptome Perspective'. The Journal of Clinical Endocrinology and Metabolism 102 (6): 2029-38. https://doi.org/10.1210/jc.20163524.

Samuelsson, Anne-Maj, Phillippa A. Matthews, Marco Argenton, Michael R. Christie, Josie M. McConnell, Eugene H. J. M. Jansen, Aldert H. Piersma, et al. 2008. 'Diet-Induced Obesity in Female Mice Leads to Offspring Hyperphagia, Adiposity, Hypertension, and Insulin Resistance: A Novel Murine Model of Developmental Programming'. Hypertension (Dallas, Tex.: 1979) 51 (2): 383-92. https://doi.org/10.1161/HYPERTENSIONAHA.107.101477.

Sanfins, Alexandra, Patrícia Rodrigues, and David F. Albertini. 2018. 'GDF-9 and BMP-15 Direct the Follicle Symphony'. Journal of Assisted Reproduction and Genetics 35 (10): 1741-50. https://doi.org/10.1007/s10815-018-1268-4.

Schmidt, Rebecca L., and Laurel L. Lenz. 2012. 'Distinct Licensing of IL-18 and IL-1 $\beta$ Secretion in Response to NLRP3 Inflammasome Activation'. PLOS ONE 7 (9): e45186. https://doi.org/10.1371/journal.pone.0045186.

Shao, Bo-Zong, Zhe-Qi Xu, Bin-Ze Han, Ding-Feng Su, and Chong Liu. 2015. 'NLRP3 Inflammasome and Its Inhibitors: A Review'. Frontiers in Pharmacology 6 (November). https://doi.org/10.3389/fphar.2015.00262. 
Shen, Hao-Ran, Xiao Xu, and Xue-Lian Li. 2021. 'Berberine Exerts a Protective Effect on Rats with Polycystic Ovary Syndrome by Inhibiting the Inflammatory Response and Cell Apoptosis'. Reproductive Biology and Endocrinology 19 (1): 3. https://doi.org/10.1186/s12958-02000684-y.

Shuvarikov, Andrey A., Michael A. Davis, Katharina Esser-Nobis, and Michael J. Gale. 2018. 'Mitochondrial SLC25 Proteins Interact with NLRP3 to Regulate Inflammasome Function'. The Journal of Immunology 200 (1 Supplement): 115.8-115.8.

Smith, Reuben L, Maarten R Soeters, Rob C I Wüst, and Riekelt H Houtkooper. 2018. 'Metabolic Flexibility as an Adaptation to Energy Resources and Requirements in Health and Disease'. Endocrine Reviews 39 (4): 489-517. https://doi.org/10.1210/er.2017-00211.

Snider, Alexandria P., and Jennifer R. Wood. 2019. 'Obesity Induces Ovarian Inflammation and Reduces Oocyte Quality'. Reproduction (Cambridge, England) 158 (3): R79-90. https://doi.org/10.1530/REP-18-0583.

Stienstra, Rinke, Cees J. Tack, Thirumala-Devi Kanneganti, Leo A. B. Joosten, and Mihai G. Netea. 2012. 'The Inflammasome Puts Obesity in the Danger Zone'. Cell Metabolism 15 (1): 10-18. https://doi.org/10.1016/j.cmet.2011.10.011.

Tőzsér, József, and Szilvia Benkő. 2016. 'Natural Compounds as Regulators of NLRP3 Inflammasome-Mediated IL-1 $\beta$ Production'. Mediators of Inflammation 2016: 5460302. https://doi.org/10.1155/2016/5460302.

Traba, Javier, and Michael N. Sack. 2017. 'The Role of Caloric Load and Mitochondrial Homeostasis in the Regulation of the NLRP3 Inflammasome'. Cellular and Molecular Life Sciences: CMLS 74 (10): 1777-91. https://doi.org/10.1007/s00018-016-2431-7.

Uyar, Asli, Saioa Torrealday, and Emre Seli. 2013. 'Cumulus and Granulosa Cell Markers of Oocyte and Embryo Quality'. Fertility and Sterility 99 (4): 979-97. https://doi.org/10.1016/j.fertnstert.2013.01.129.

Wang, F., S. Wang, Z. Zhang, Q. Lin, Y. Liu, Y. Xiao, K. Xiao, and Zhengchao Wang. 2017. 'Activation of NLRP3 Inflammasome in the Ovaries during the Development and Treatment of Polycystic Ovary Syndrome'. International Journal of Clinical and Experimental Pathology 10 (January): 5022-30.

Wang, Xiaqiong, Wei Jiang, Yiqing Yan, Tao Gong, Jiahuai Han, Zhigang Tian, and Rongbin Zhou. 2014. 'RNA Viruses Promote Activation of the NLRP3 Inflammasome through a RIP1-RIP3DRP1 Signaling Pathway'. Nature Immunology $15 \quad$ (12): 1126-33. https://doi.org/10.1038/ni.3015.

Wani, Kaiser, Hind AlHarthi, Amani Alghamdi, Shaun Sabico, and Nasser M. Al-Daghri. 2021. 'Role of NLRP3 Inflammasome Activation in Obesity-Mediated Metabolic Disorders'. International Journal of Environmental Research and Public Health 18 (2). https://doi.org/10.3390/ijerph18020511.

Weber, Alexander N. R., Zsófia A. Bittner, Sangeetha Shankar, Xiao Liu, Tzu-Hsuan Chang, Tengchuan Jin, and Ana Tapia-Abellán. 2020. 'Recent Insights into the Regulatory Networks of NLRP3 Inflammasome Activation'. Journal of Cell Science 133 (jcs248344). https://doi.org/10.1242/jcs.248344.

Wen, Haitao, Denis Gris, Yu Lei, Sushmita Jha, Lu Zhang, Max Tze-Han Huang, Willie June Brickey, and Jenny P.-Y. Ting. 2011. 'Fatty Acid-Induced NLRP3-ASC Inflammasome Activation Interferes with Insulin Signaling'. Nature Immunology 12 (5): 408-15. https://doi.org/10.1038/ni.2022.

Wilding, Martin, Gianfranco Coppola, Brian Dale, and Loredana Di Matteo. 2009. 'Mitochondria and Human Preimplantation Embryo Development'. Reproduction (Cambridge, England) 137 (4): 619-24. https://doi.org/10.1530/REP-08-0444. 
804

805

806

807

808

809

810

811

812

813

814

815

816

817

818

819

820

821

822

823

824

825

826

827

828

829

830

831

832

833

834

835

836

837

838

839

840

841

842

843

844

845

846

847

848

849

850

Wolf, Andrea J., Christopher N. Reyes, Wenbin Liang, Courtney Becker, Kenichi Shimada, Matthew L. Wheeler, Hee Cheol Cho, et al. 2016. 'Hexokinase Is an Innate Immune Receptor for the Detection of Bacterial Peptidoglycan'. Cell $166 \quad$ (3): 624-36. https://doi.org/10.1016/j.cell.2016.05.076.

Wołodko, Karolina, Juan Castillo-Fernandez, Gavin Kelsey, and António Galvão. 2021. 'Revisiting the Impact of Local Leptin Signaling in Folliculogenesis and Oocyte Maturation in Obese Mothers'. International Journal of Molecular Sciences 22 (8). https://doi.org/10.3390/ijms22084270.

Wołodko, Karolina, Edyta Walewska, Marek Adamowski, Juan Castillo-Fernandez, Gavin Kelsey, and António Galvão. 2020. 'Leptin Resistance in the Ovary of Obese Mice Is Associated with Profound Changes in the Transcriptome of Cumulus Cells'. Cellular Physiology and Biochemistry: International Journal of Experimental Cellular Physiology, Biochemistry, and Pharmacology 54 (3): 417-37. https://doi.org/10.33594/000000228.

Wu, Linda Lin-Yan, Kylie R. Dunning, Xing Yang, Darryl L. Russell, Michelle Lane, Robert J. Norman, and Rebecca L. Robker. 2010. 'High-Fat Diet Causes Lipotoxicity Responses in Cumulus-Oocyte Complexes and Decreased Fertilization Rates'. Endocrinology 151 (11): 5438-45. https://doi.org/10.1210/en.2010-0551.

Yamaguchi, A., O. Hori, D. M. Stern, E. Hartmann, S. Ogawa, and M. Tohyama. 1999. 'StressAssociated Endoplasmic Reticulum Protein 1 (SERP1)/Ribosome-Associated Membrane Protein 4 (RAMP4) Stabilizes Membrane Proteins during Stress and Facilitates Subsequent Glycosylation'. The Journal of Cell Biology 147 (6): 1195-1204. https://doi.org/10.1083/jcb.147.6.1195.

Yang, Ching-Chun, Chih-Hsing Wu, Ta-Chun Lin, Yi-Ning Cheng, Chin-Sung Chang, Kuo-Ting Lee, Pei-Jane Tsai, and Yau-Sheng Tsai. 2021. 'Inhibitory Effect of PPAR $\gamma$ on NLRP3 Inflammasome Activation'. Theranostics $11 \quad$ 2424-41. https://doi.org/10.7150/thno.46873.

Zhang, Tianli, Hiroyasu Tsutsuki, Waliul Islam, Katsuhiko Ono, Kohsuke Takeda, Takaaki Akaike, and Tomohiro Sawa. 2021. 'ATP Exposure Stimulates Glutathione Efflux as a Necessary Switch for NLRP3 Inflammasome Activation'. Redox Biology 41 (May): 101930. https://doi.org/10.1016/j.redox.2021.101930.

Zhang, Zhenghong, Fan Wang, and Yan Zhang. 2019. 'Expression and Contribution of NLRP3 Inflammasome During the Follicular Development Induced by PMSG'. Frontiers in Cell and Developmental Biology 7. https://doi.org/10.3389/fcell.2019.00256.

Zhao, J., and Y. Li. 2012. 'Adenosine Triphosphate Content in Human Unfertilized Oocytes, Undivided Zygotes and Embryos Unsuitable for Transfer or Cryopreservation'. The Journal of International Medical $\quad$ Research $40 \quad$ (2): $\quad$ 734-39. https://doi.org/10.1177/147323001204000238.

Zhao, Sheng, and Russell D. Fernald. 2005. 'Comprehensive Algorithm for Quantitative Real-Time Polymerase Chain Reaction'. Journal of Computational Biology: A Journal of Computational Molecular Cell Biology 12 (8): 1047-64. https://doi.org/10.1089/cmb.2005.12.1047.

Zhou, Rongbin, Aubry Tardivel, Bernard Thorens, Inpyo Choi, and Jürg Tschopp. 2010. 'Thioredoxin-Interacting Protein Links Oxidative Stress to Inflammasome Activation'. Nature Immunology 11 (2): 136-40. https://doi.org/10.1038/ni.1831.

Zhu, Qifan, and Thirumala-Devi Kanneganti. 2017. 'Cutting Edge: Distinct Regulatory Mechanisms Control Proinflammatory Cytokines IL-18 and IL-1 $\beta$ '. The Journal of Immunology 198 (11): 4210-15. https://doi.org/10.4049/jimmunol.1700352. 


\section{$851 \quad$ Figure Legends}

852 Figure 1. Morphofunctional characterisation of NLRP3 in the ovary of cyclic mice

853 (A) Experimental design: oestrous cycle synchronisation with eCG and hCG as previously described 854 (Hasegawa et al. 2016). Ovaries were collected from animals in oestrus (E) or dioestrus (D) stage of 855 the cycle. Quantification of mRNA levels of (B) Nod-Like Receptor Protein 3 (Nlrp3), caspase-1 856 (Casp1), interleukin-1 $\beta(I l-1 \beta)$, interleukin-18 (Il-18) by real-time PCR. Abundance of (C) Nod-Like 857 Receptor Protein 3 (NLRP3), (D) pro IL-18 p24, (E) IL-18 p18, (F) pro CASP1 p45 and (G) CASP1 p20 protein during E and D measured by western blotting analysis. Data was normalized to ribosomal protein L37 (Rpl37) mRNA expression and $\beta$-actin of or glyceraldehyde 3-phosphate dehydrogenase $($ GAPDH) protein expression. Bars represent mean \pm SEM. Statistical analysis between groups was carried out using Mann-Whitney. $\mathrm{n}=5-7$ for real-time PCR analysis and $\mathrm{n}=6$ for immunoblots. Asterisks indicate significant differences $(* \mathrm{p}<0.05 ; * * \mathrm{p}<0.01)$. Representative immunohistochemical staining of NLRP3 protein during follicular development in the mouse ovary. Positive staining in brown, counterstaining with heamatoxylin. (H, J) Negative control incubated with secondary antibody. Localisation of NLRP3 in (I) whole ovary of 16 weeks (wk) mice fed chow diet (CD), (K) primary follicles of $16 \mathrm{wk}$ CD mice, (L) secondary follicles of $16 \mathrm{wk}$ high fat diet (HFD) mice, and (M) preantral follicles of $16 \mathrm{wk}$ CD mice. Staining was detected in granulosa and theca cells. Faint staining was observed in the oocytes of all stages of folliculogenesis. Arrows denote granulosa cells, arrow-heads denote theca cells, asterisks denote oocytes. The immunohistochemistry staining was confirmed by immunofluorescent localisation of NLRP3. Positive staining in orange, nuclear counterstaining with DAPI in blue. (N) Negative control 16 wk CD stained with polyclonal rabbit IgG. NLRP3 localised in (O) whole ovary, (P-Q) secondary follicles of 16 wk CD mice, (R-S) preantral follicles of 16 wk HFD mice, (T-U) antral follicles of 16 wk HFD mice. Inserts in top left corners represent magnifications of granulosa cells. Scale bars represent 20 or $100 \mu \mathrm{m}$.

876 Figure 2. Diet induced-obesity changes NLRP3 expression in the ovary

877 (A) Experimental design: mice were fed either chow diet (CD) or high fat diet (HFD) for 4 weeks 878 (wk) or $16 \mathrm{wk}$ and ovaries were collected during dioestrus stage. Quantification of (B) Nod-Like

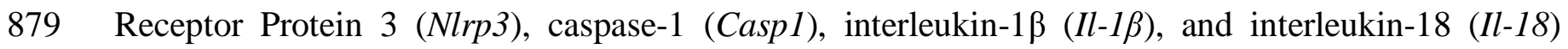
880 mRNA by real-time PCR. Abundance of (C) NLRP3, (D) pro CASP1 p45, (E) CASP1 p20, (F) pro 
881 IL-18 p24, (G) IL-18 p18 protein measured by western blotting and (H) IL-1 $\beta$ protein measured by

882 ELISA in ovarian extracts collected from DIO mice. mRNA level was normalized with ribosomal

883 protein L37 (Rpl37) value and protein expression with $\beta$-actin or glyceraldehyde 3-phosphate

884 dehydrogenase (GAPDH) level. Bars represent mean \pm SEM. Differences between control and

885 treatment groups analysed with Mann-Whitney; $n=6-9$ for real-time PCR analysis, $n=8$ for

886 immunoblots and $\mathrm{n}=6$ for ELISA. Asterisks indicate significant differences $(* \mathrm{p}<0.05 ; * * \mathrm{p}<0.01$;

$887+\mathrm{p}=0.06 ;+\mathrm{p}=0.07$ or $+\mathrm{p}=0.082-$ all values indicated $)$.

888

889 Figure 3. Leptin signalling in the ovary drive changes of NLRP3 during obesity

890 A) Experimental design: i) pharmacological hyperleptinemia model, mice were either injected with 891 saline or $100 \mu \mathrm{g}$ of leptin (L) for 16 days ; and ii) genetic obesity model, mice lacking leptin in 892 circulation (ob/ob -/-) or control group (ob/ob +/?). B) Heatmap illustrating fold of change in 893 expression of mRNA of genes Nod-Like Receptor Protein 3 (Nlrp3), caspase-1 (Casp1), interleukin$8941 \beta(I l-1 \beta)$, interleukin-18 (Il-18), apoptosis-associated speck-like protein containing A CARD (Asc), 895 interleukin-10 (Il-10) and tumour necrosis factor alpha (Tnf) in hyperleptinemia and $o b / o b$ models 896 determined by real-time PCR. The scale matches colours to log 2 fold change ( $\log 2$ FC) values. 897 Abundance of (C) NLRP3, (D) pro CASP1 p45, (E) CASP1 p20 measured by wersten blotting and 898 (F) Il-1 $\beta$ quantified by EIA, in the mouse ovarian extracts. Level mRNA normalized with ribosomal 899 protein L37 (Rpl37) value and protein expression with $\beta$-actin or glyceraldehyde 3-phosphate 900 dehydrogenase $($ GAPDH) . Bars represent mean \pm SEM. Statistical analysis between groups was 901 carried out using Mann-Whitney test. $n=6-9$ for real-time PCR analysis and $n=4-8$ for immunoblots. 902 Asterisks indicate significant differences $(* \mathrm{p}<0.05 ;+\mathrm{p}=0.07)$.

904 Figure 4. Cumulus cells transcriptome analysis from diet- induced obese and pharmacologically 905 hyperleptinemic mice reveals leptin-mediated regulation of NLRP3 inflammasome genes

906 A) Experimental design: RNA-Seq analysis of differentially expressed genes in cumulus cells 907 collected from mice: i) with diet- induced obesity (DIO) fed chow diet (CD) or high fat diet (HFD) 908 for 4 weeks (wk) or 16 wk ii) with pharmacologically hyperleptinemic (LEPT) injected with saline 909 (C) or $100 \mu \mathrm{g}$ of leptin (L) for 16 days. B) Heatmap illustrating expression of genes from leptin 
910 signalling pathway and NLRP3 inflammasome in LEPT and 4 wk HFD normalized by control group

911 fed CD or injected with saline, respectively. Downregulated genes in blue, upregulated genes in

912 orange. The scale on the right matches colours to log 2 fold change (log2 FC) values. (C) Heatmap

913 showing significant changes in major constitutive genes in both conditions leptin and 4 wk HFD. (D)

914 Five main clusters in the network representing strong interaction between selected genes described in

915 B and genes presented in C. (E) Pie chart that displays the main three gene ontology terms that were

916 significantly enriched in cumulus cells in both conditions LEPT and 4 wk HFD. Gene ontology

917 analysis performed with Gene Ontology Enrichment Analysis and Visualisation Tool. (F) Heatmaps

918 showing conserved genes involved in NLRP3 inflammasome activation, glutathione metabolism and

919 other regulations. $\log 2 \mathrm{FC}$ of reads per million (RPM).

920

921 Figure 5. NLRP3 activity in the liver of diet- induced obese, hyperleptinemic and genetically obese 922 mice

923 (A)Experimental design: i) diet induced obese (DIO) mice were fed chow diet (CD) or high fat diet

924 (HFD) for 4 weeks (wk) or $16 \mathrm{wk}$; ii) pharmacologically hyperleptinemic mice were treated with 925 saline (C) or $100 \mu \mathrm{g}$ of leptin (L) for 16 days; iii) genetically obese mice lacking leptin (ob/ob -/-) and 926 control group $(o b / o b+/$ ?). (B) Heatmap illustrating fold change in expression of mRNA of genes

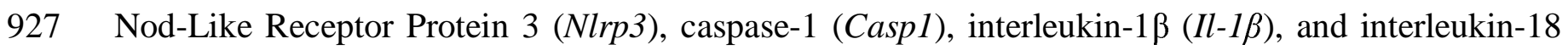
928 (Il-18), apoptosis-associated speck-like protein containing a CARD (Asc), interleukin-10 (Il-10) and 929 tumour necrosis factor alpha (Tnf) in DIO, hyperleptinemia and $o b / o b$ models in comparison to 930 respective controls, determined by real-time PCR. The scale on the right matches colours to $\log 2$ fold 931 change $(\log 2$ FC) values. Data normalised to mRNA expression of ribosomal protein L37 (Rpl37).

932 Abundance of (C) NLRP3, (D) pro CASP1 p45, (E) CASP1 p20, (F) pro IL-18 p24 in mouse liver of

933 DIO, hyperleptinemic and $o b / o b$ mice measured in western blotting analysis. Protein normalised with

$934 \beta$-actin or glyceraldehyde 3-phosphate dehydrogenase (GAPDH) level. Bars represent mean \pm SEM.

935 Statistical analysis between groups was carried out using Mann-Whitney test; $n=6-9$ for real-time 936 PCR analysis and $\mathrm{n}=5-8$ for immunoblots. Asterisks indicate significant differences $\left({ }^{*} \mathrm{p}<0.05\right.$; $937 * * \mathrm{p}<0.01)$.

939 Table 1. Specification of antibodies used for Western blotting. 


\begin{tabular}{|c|l|c|}
\hline $\begin{array}{c}\text { Antibody name and specificity } \\
\text { Mouse monoclonal against NLR } \\
\text { family pyrin domain containing 3 } \\
\text { (NLRP3) }\end{array}$ & $\begin{array}{l}\text { Company, Cat no, RRID no } \\
\text { RRID:AB_2490202 }\end{array}$ & Antibody dilution \\
\hline Rabbit monoclonal against Caspase 1 & $\begin{array}{l}\text { Abcam Cat\# ab108362, } \\
\text { RRID:AB_10858984 }\end{array}$ & $1: 1000$ \\
\hline $\begin{array}{c}\text { Rabbit polyclonal against } \\
\text { interleukin-18 (IL-18) }\end{array}$ & $\begin{array}{l}\text { Abcam Cat\# ab71495, } \\
\text { RRID:AB_1209302 }\end{array}$ & $1: 1000$ \\
\hline $\begin{array}{c}\text { Mouse monoclonal against } \\
\text { Rabbit polyclonal against } \\
\text { glyceraldehyde 3-phosphate } \\
\text { dehydrogenase (GAPDH) }\end{array}$ & $\begin{array}{l}\text { Sigma-Aldrich Cat\# A2228, } \\
\text { RRID:AB_476697 }\end{array}$ & $1: 10000$ \\
\hline $\begin{array}{c}\text { Goat anti-Mouse IgG (H+L) } \\
\text { Secondary Antibody, HRP }\end{array}$ & $\begin{array}{l}\text { Thermo Fisher Scientific Cat\# } \\
\text { 31430, RRID:AB_228307 }\end{array}$ & $1: 2500$ \\
\hline $\begin{array}{c}\text { Goat anti-Rabbit IgG (H+L) } \\
\text { Secondary Antibody, HRP }\end{array}$ & $\begin{array}{l}\text { Thermo Fisher Scientific Cat\# } \\
\text { 31460, RRID:AB_228341 }\end{array}$ & $1: 1000$ \\
\hline $\begin{array}{c}\text { Goat anti-Mouse IgG (H+L) } \\
\text { Secondary Antibody, AP }\end{array}$ & $\begin{array}{l}\text { Thermo Fisher Scientific Cat\# } \\
\text { 31321, RRID:AB_10959407 }\end{array}$ & $1: 20000$ \\
\hline $\begin{array}{c}\text { Goat Anti-Rabbit IgG (whole } \\
\text { molecule) Secondary Antibody, AP }\end{array}$ & $\begin{array}{l}\text { Sigma-Aldrich Cat\# A3687, } \\
\text { RRID:AB_258103 }\end{array}$ & $1: 1000$ \\
\hline
\end{tabular}

941

942

943

944

945

946

947

948

949

950

951

952 
bioRxiv preprint doi: https://doi.org/10.1101/2021.08.16.456479; this version posted August 17, 2021. The copyright holder for this preprint (which was not certified by peer review) is the author/funder, who has granted bioRxiv a license to display the preprint in perpetuity. It is made available under aCC-BY-NC-ND 4.0 International license.

953

\begin{tabular}{|c|c|c|c|c|}
\hline Gene name & $\begin{array}{c}\text { Gene } \\
\text { symbol }\end{array}$ & $\begin{array}{c}\text { GenBank } \\
\text { Accession no. }\end{array}$ & Sequences 5'-3, & $\begin{array}{c}\text { Length } \\
\text { (base } \\
\text { pairs) }\end{array}$ \\
\hline
\end{tabular}

962 Table 2. Specific primers used for quantitative real-time PCR.

963

964

965 
bioRxiv preprint doi: https://doi.org/10.1101/2021.08.16.456479; this version posted August 17, 2021. The copyright holder for this preprint (which was not certified by peer review) is the author/funder, who has granted bioRxiv a license to display the preprint in perpetuity. It is made available under aCC-BY-NC-ND 4.0 International license.

\begin{tabular}{|c|c|c|c|c|}
\hline $\begin{array}{l}\text { NLR family } \\
\text { pyrin domain } \\
\text { containing } 3\end{array}$ & Nlrp3 & NM_145827.4 & $\begin{array}{l}\text { F: TGGATGGGTTTGCTGGGATA } \\
\text { R: TGCTTGGATGCTCCTTGACC }\end{array}$ & 190 \\
\hline Caspase 1 & Caspl & NM_009807.2 & $\begin{array}{l}\text { F: CATGCCGTGGAGAGAAACAA } \\
\text { R: GGTGTTGAAGAGCAGAAAGCAA }\end{array}$ & 151 \\
\hline Interleukin-1 $\beta$ & $I L-1 \beta$ & NM_008361.4 & $\begin{array}{l}\text { F: TTGACGGACCCCAAAAGATG } \\
\text { R: GCTTCTCCACAGCCACAATGA }\end{array}$ & 144 \\
\hline Interleukin-18 & Il-18 & NM_008360.2 & $\begin{array}{l}\text { F: GAAGAAAATGGAGACCTGGAATCA } \\
\text { R: TCTGGGGTTCACTGGCACTT }\end{array}$ & 157 \\
\hline $\begin{array}{c}\text { Apoptosis- } \\
\text { Associated } \\
\text { Speck-Like } \\
\text { Protein } \\
\text { Containing A } \\
\text { CARD }\end{array}$ & Asc & NM_023258.4 & $\begin{array}{l}\text { F: GCTTAGAGACATGGGCTTACAGGA } \\
\text { R: CCAGCACTCCGTCCACTTCT }\end{array}$ & 179 \\
\hline Interleukin-10 & Il-10 & NM_010548.2 & $\begin{array}{l}\text { F: CCTGGGTGAGAAGCTGAAGAC } \\
\text { R: CTGCTCCACTGCCTTGCTCT }\end{array}$ & 91 \\
\hline $\begin{array}{l}\text { Tumor necrosis } \\
\text { factor }\end{array}$ & $\operatorname{Tnf}$ & NM_001278601.1 & $\begin{array}{l}\text { F: GCCACCACGCTCTTCTGTCT } \\
\text { R: TGAGGGTCTGGGCCATAGAA }\end{array}$ & 106 \\
\hline $\begin{array}{l}\text { Ribosomal } \\
\text { protein } \\
\text { L37 }\end{array}$ & Rpl37 & NM_026069.3 & $\begin{array}{l}\text { F:CTGGTCGGATGAGGCACCTA } \\
\text { R: AAGAACTGGATGCTGCGACA }\end{array}$ & 108 \\
\hline
\end{tabular}

966

967 Table 3. Body weight measurement of 3 mouse models

968 Diet induced obese (DIO) mice were fed chow diet (CD) or high fat diet (HFD); ii) 969 pharmacologically hyperleptinemic mice were treated with saline (C) or leptin (L) for 16 days; iii)

970 genetically obese mice lacking leptin (ob/ob -/-) and control group (ob/ob $+/$ ? $)$. Statistical analysis

971 between groups was carried out using T-test. Asterisks indicate significant differences $(* * \mathrm{p}<0.01$;

$972 * * * \mathrm{p}<0.001 ; * * * * \mathrm{p}<0.0001)$.

973 
bioRxiv preprint doi: https://doi. org/10.1101/2021.08.16.456479; this version posted August 17, 2021. The copyright holder for this preprint (which was not certified by peer review) is the author/funder, who has granted bioRxiv a license to display the preprint in perpetuity. It is made available under aCC-BY-NC-ND 4.0 International license.

974

\begin{tabular}{|c|c|c|c|c|c|}
\hline & $0 \mathrm{wk}$ & $4 \mathrm{wk}$ & $8 w k$ & $12 \mathrm{wk}$ & $16 \mathrm{wk}$ \\
\hline CD & $17.0( \pm 0.6)$ & $19.7( \pm 1.0)$ & $20.0( \pm 0.9)$ & $20.9( \pm 1.0)$ & $22.6( \pm 2.5)$ \\
\hline HFD & $19.4( \pm 0.8)$ & $24.8( \pm 2.5)^{* * * *}$ & $29.1( \pm 3.6)^{* * * * *}$ & $33.1( \pm 4.3)^{* * * * *}$ & $37.6( \pm 3.7) * * * *$ \\
\hline & $\mathbf{0 d}$ & $3 \mathrm{~d}$ & $9 \mathrm{~d}$ & $12 \mathrm{~d}$ & $16 \mathrm{~d}$ \\
\hline $\bar{C}$ & $21.7( \pm 1.7)$ & $22.8( \pm 2.0)$ & $22.1( \pm 2.1)$ & $21.5( \pm 1.6)$ & $21.9( \pm 1.9)$ \\
\hline $\mathbf{L}$ & $21.8( \pm 1.9)$ & $20.5( \pm 1.9)$ & $19.0( \pm 1.4)^{* *}$ & $18.5( \pm 1.2)^{* * *}$ & $19.4( \pm 1.7)$ \\
\hline & 8 wk & 9 wk & $10 \mathrm{wk}$ & $11 \mathrm{wk}$ & $12 \mathrm{wk}$ \\
\hline ob/ob +/? & $20.9( \pm 1.6)$ & $21.5( \pm 1.6)$ & $22.2( \pm 1.6)$ & $22.8( \pm 2.1)$ & $22.7( \pm 2.1)$ \\
\hline ob/ob -/- & $39.8( \pm 5.4)^{* * * *}$ & $43.1( \pm 5.0)^{* * * *}$ & $45.0( \pm 4.7)^{* * * * *}$ & $47.4( \pm 5.7)^{* * * * *}$ & $48.8( \pm 4.0)^{* * * *}$ \\
\hline
\end{tabular}


(A)

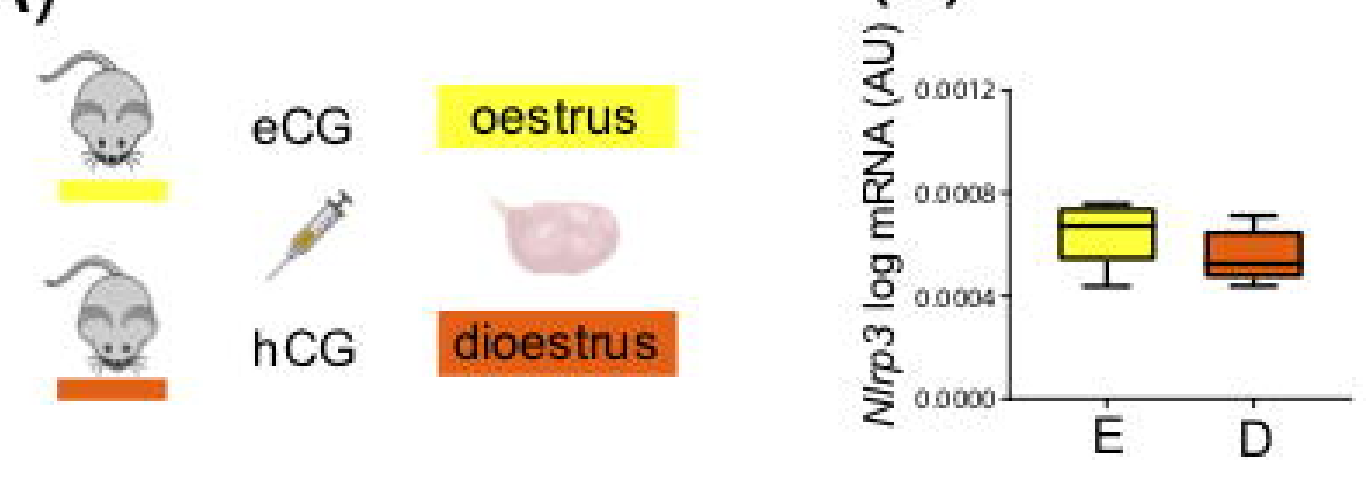

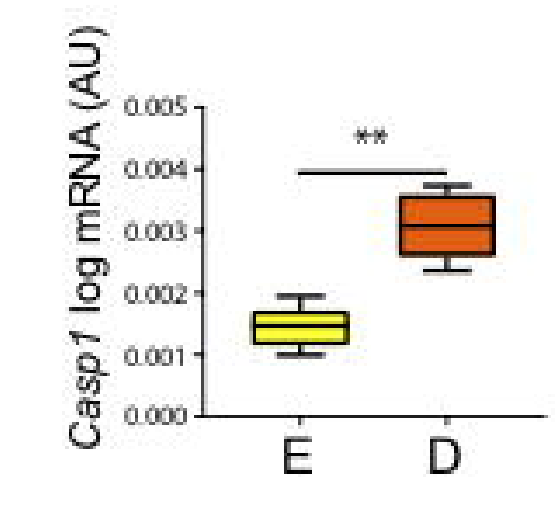

110kd NLRP3

42kd BACTIN

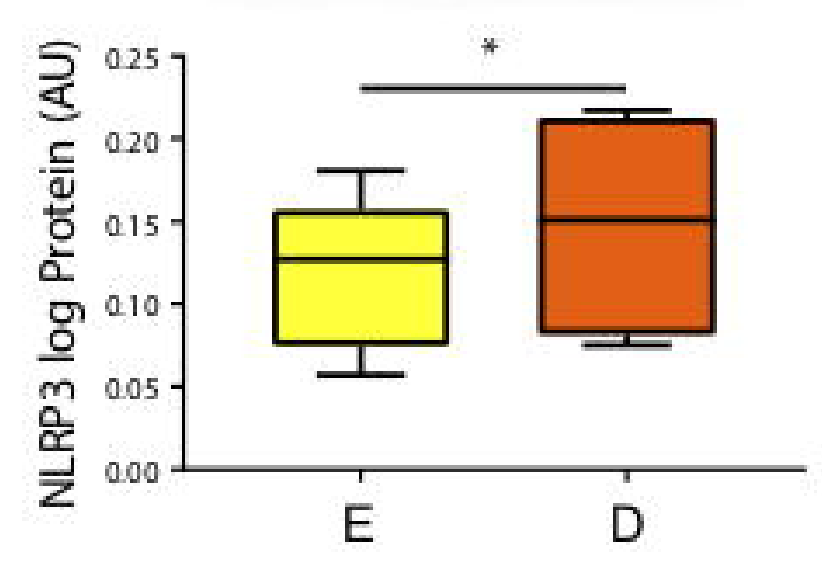

(F)
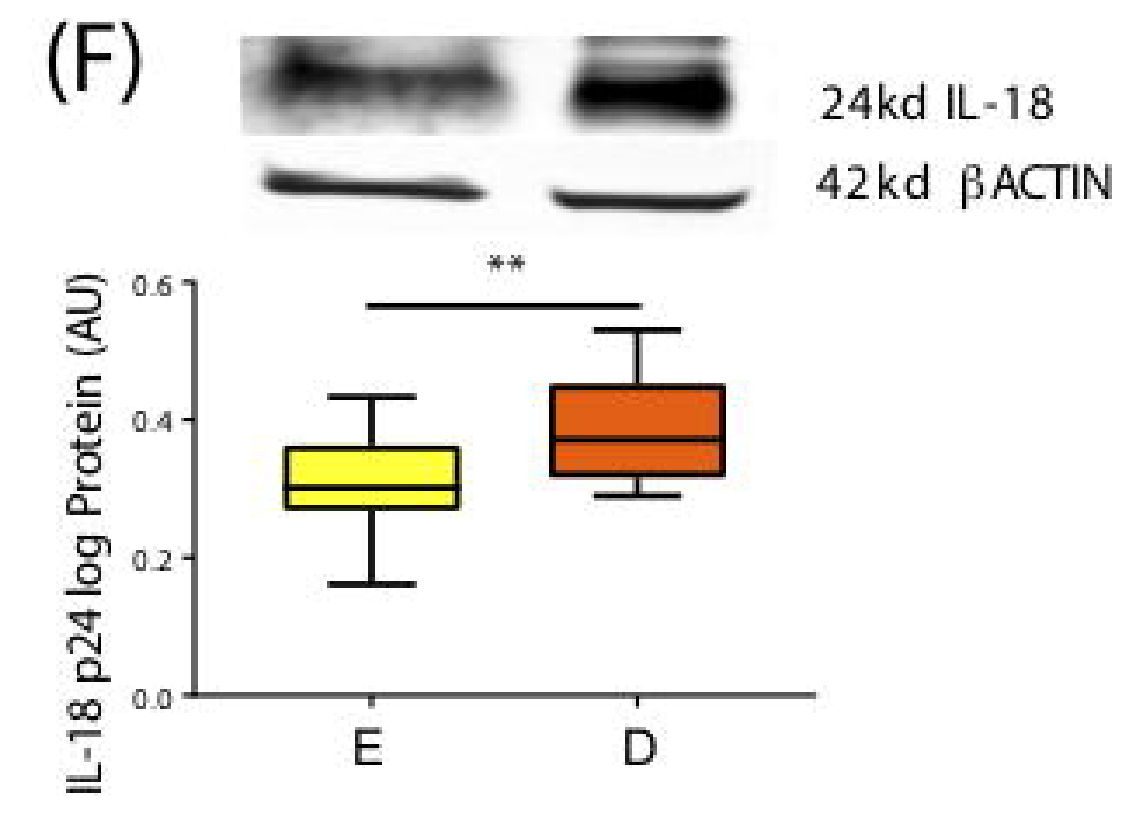

(D)
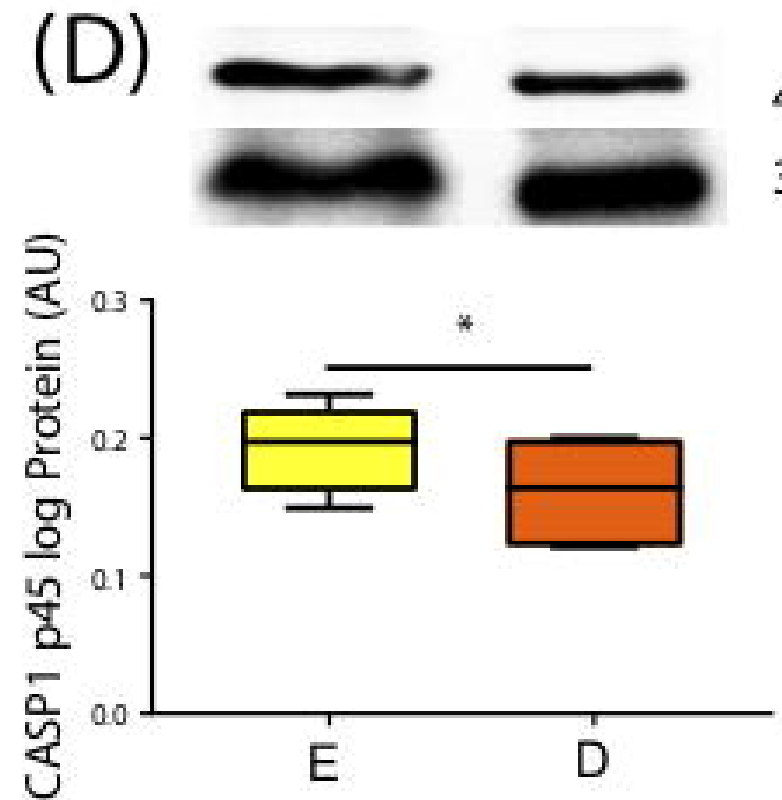

(G)
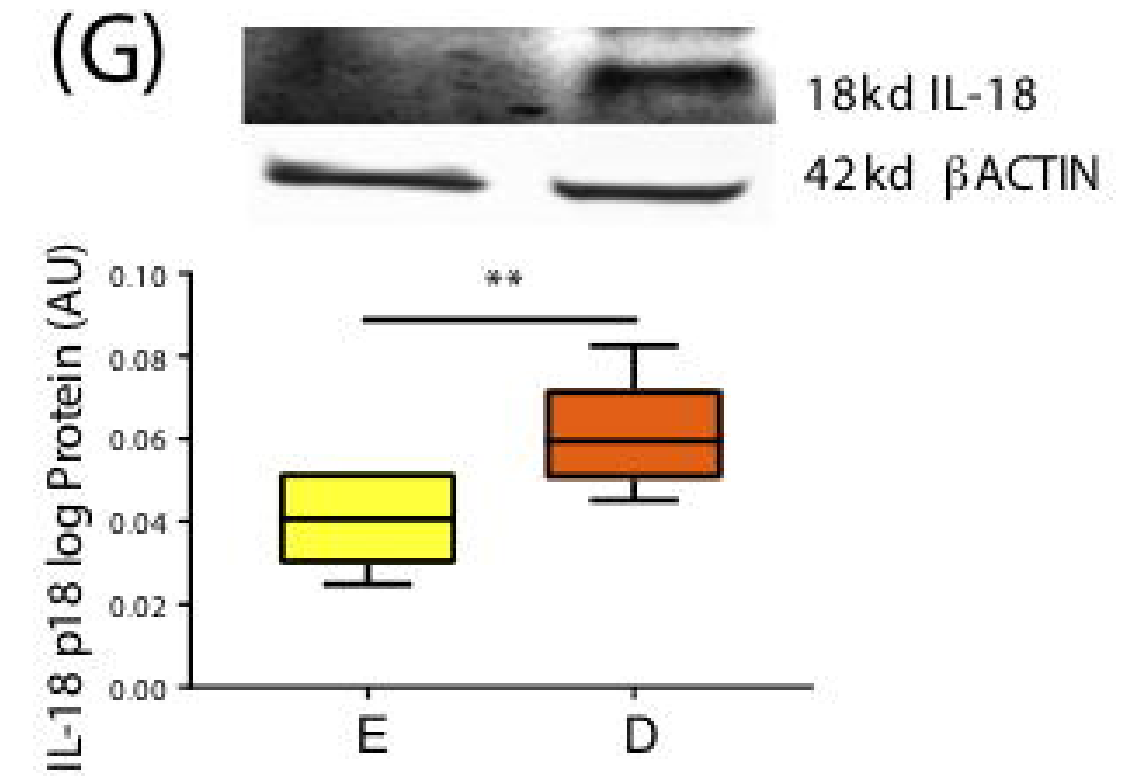

(H)
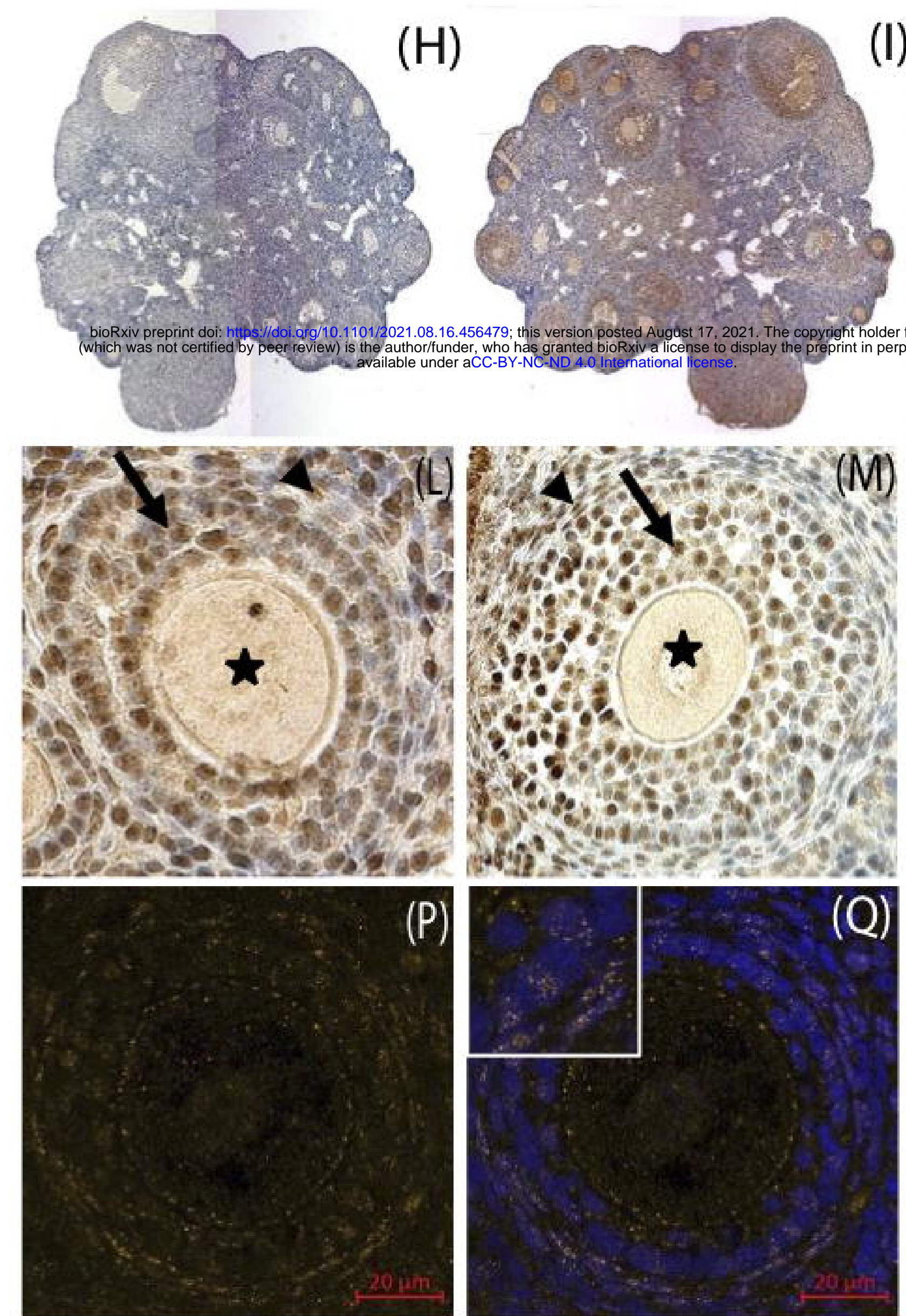

3 hos.

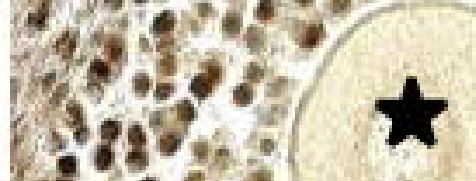

${ }^{3} 38$

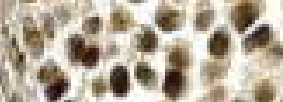

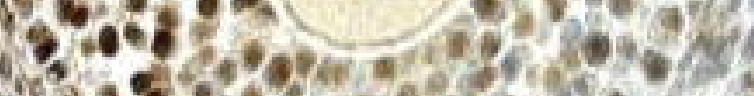

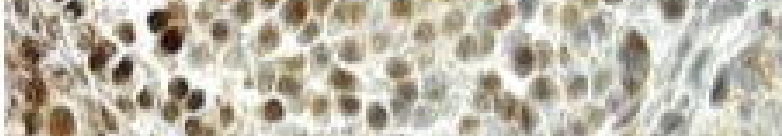

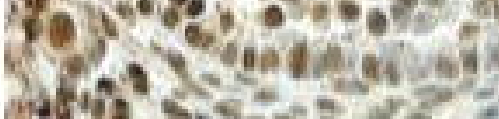
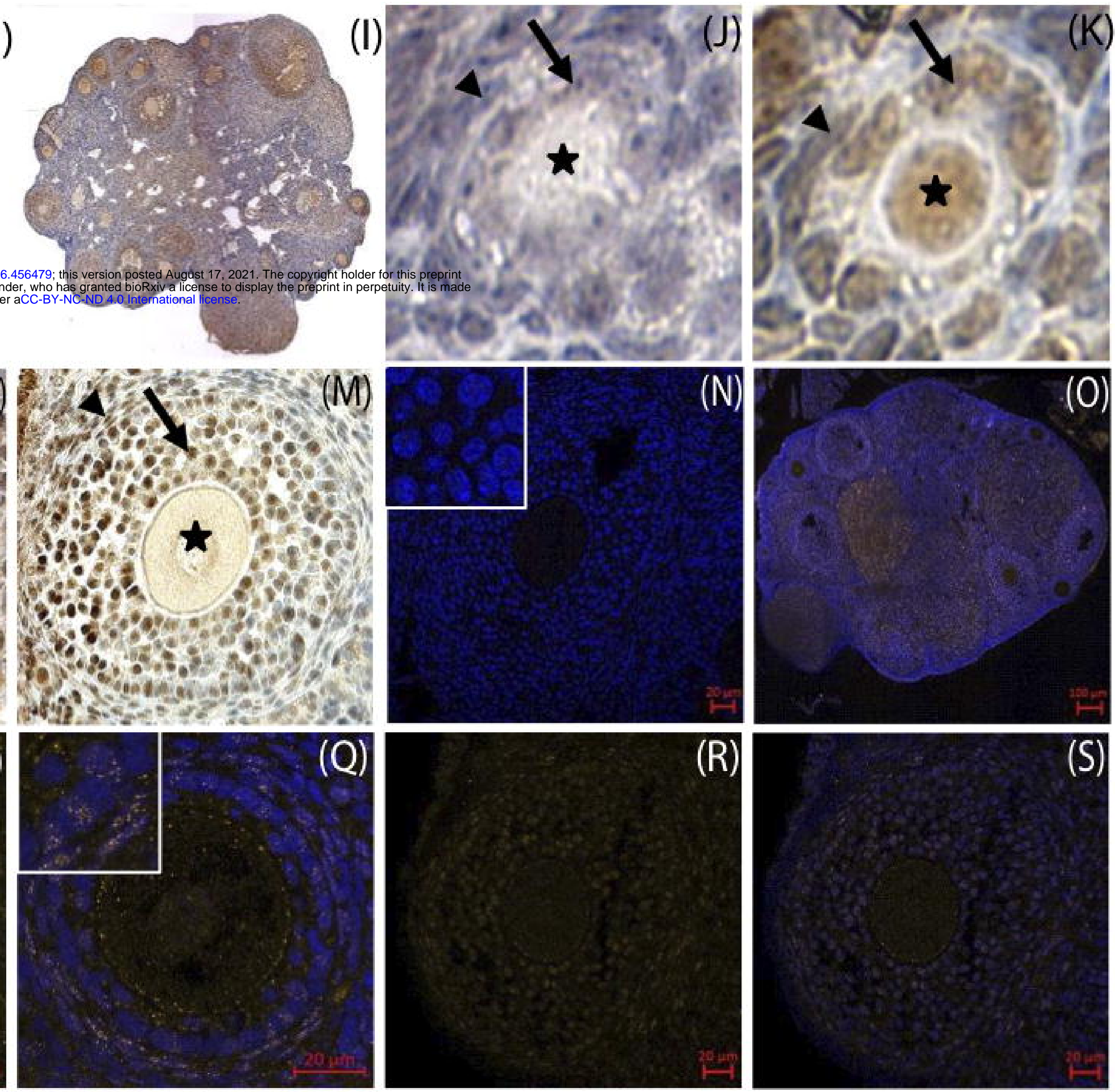

(T)

(U)

\section{)}

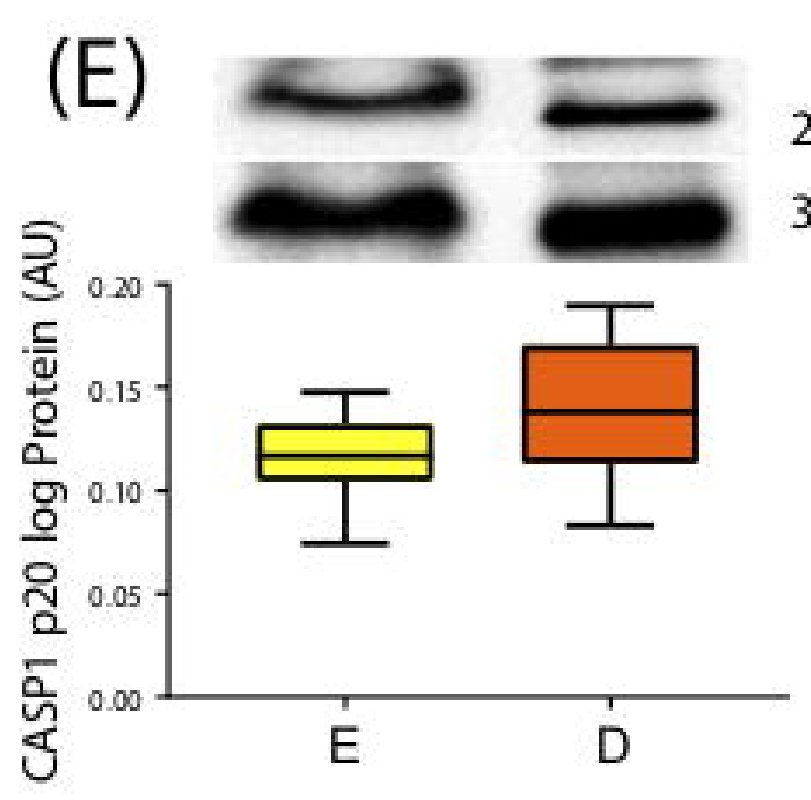

$20 \mathrm{kd}$ CASP 1 $37 \mathrm{kd} \mathrm{GAPDH}$
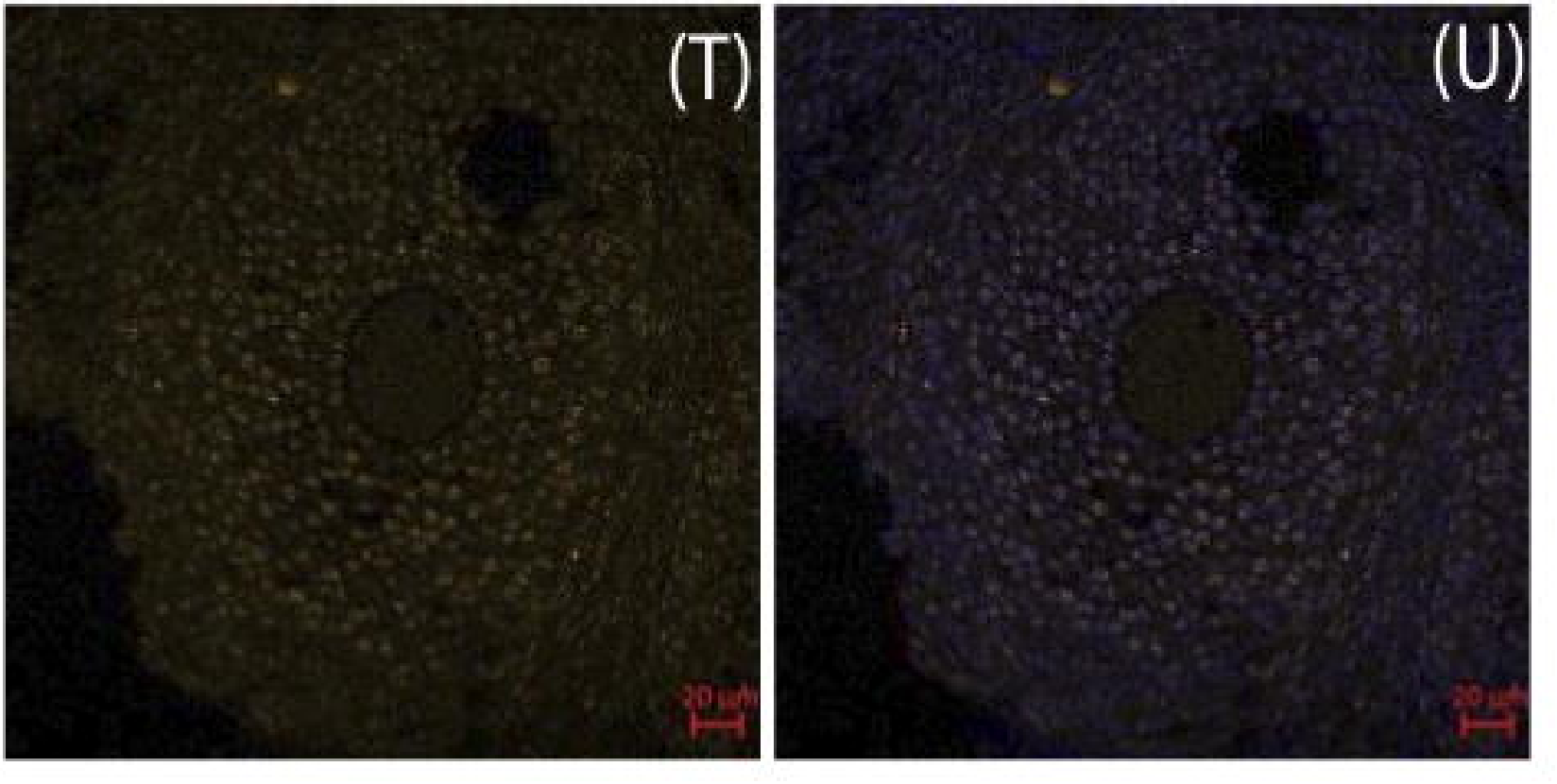
(A)

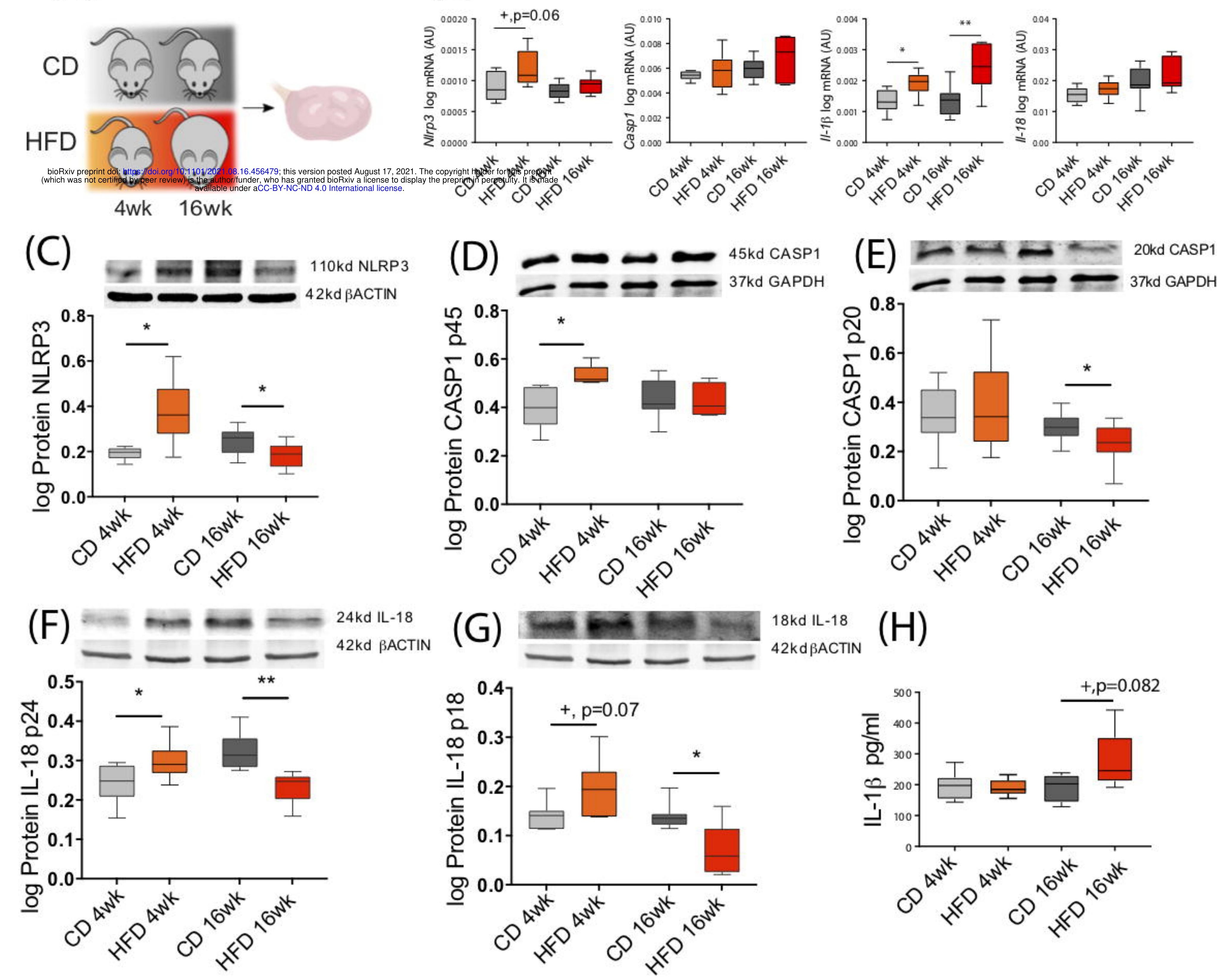


(A)

(B)

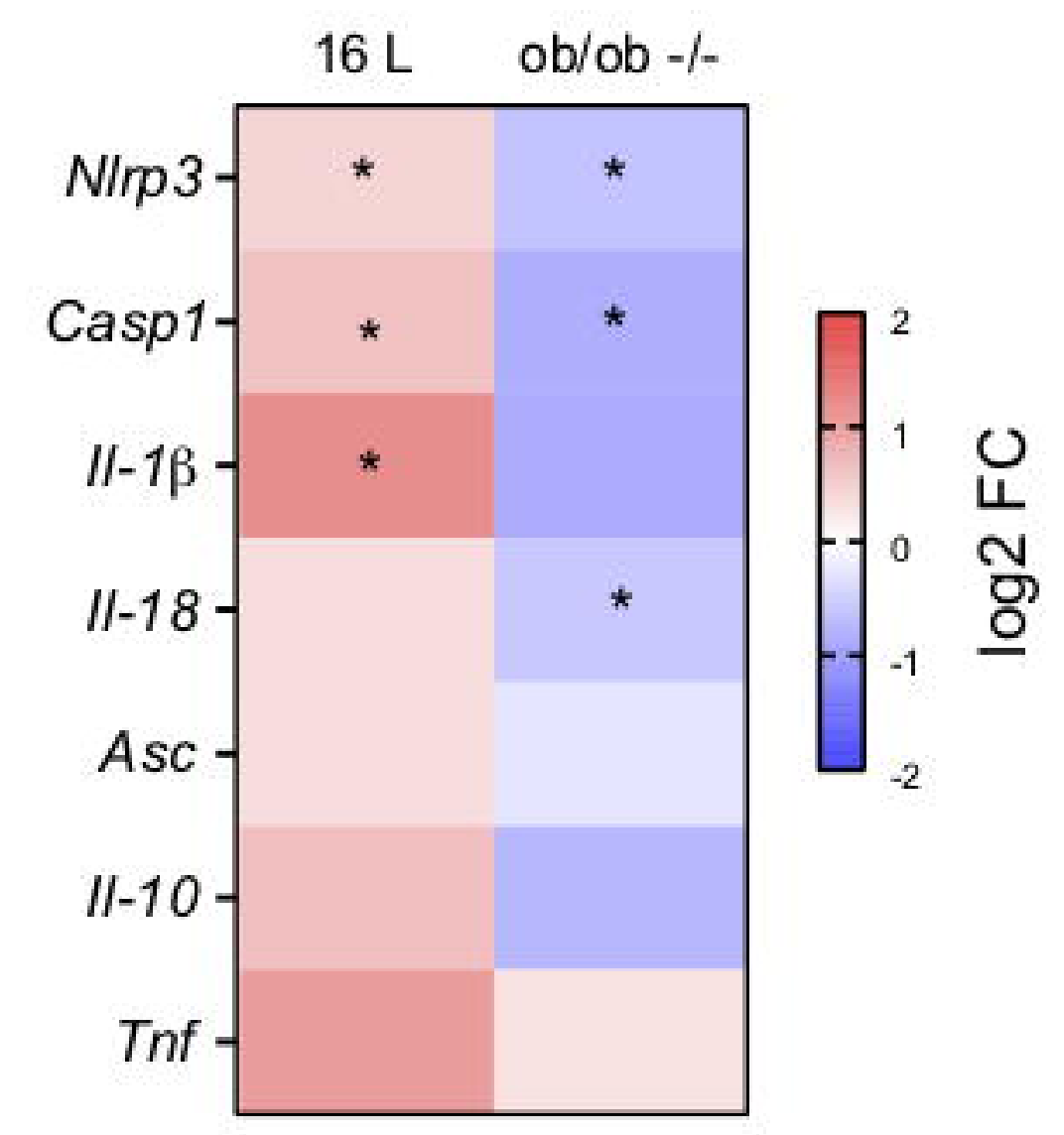

(C)

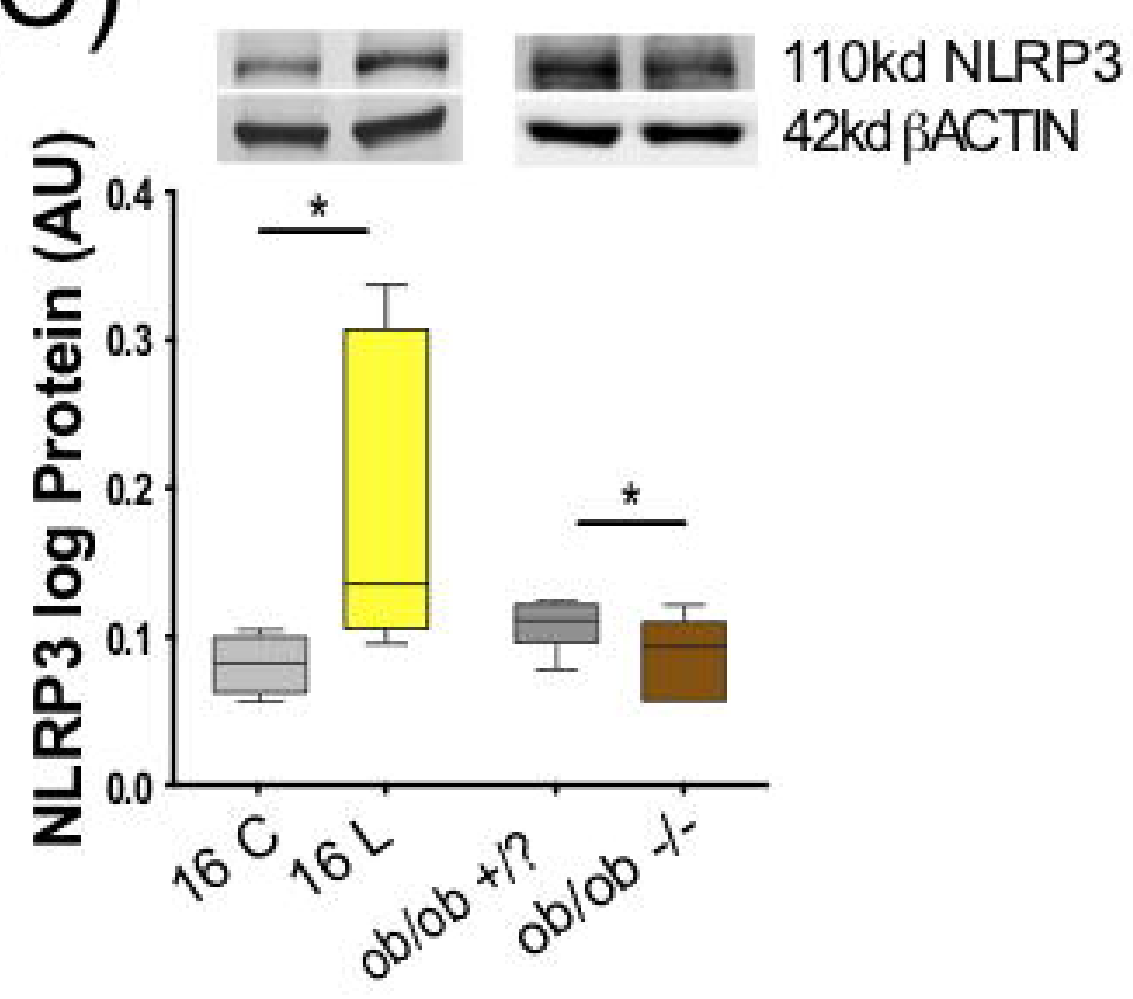

(E)

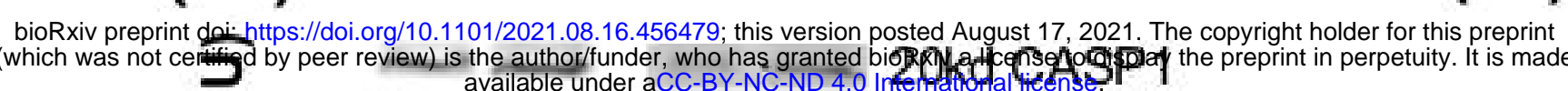

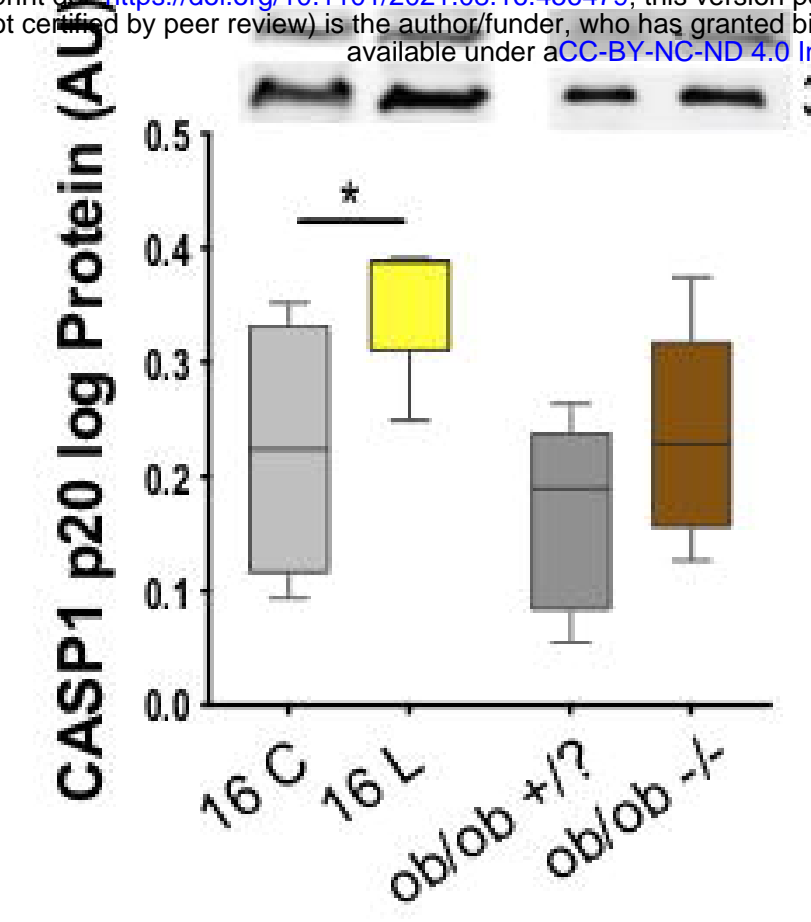

(D)

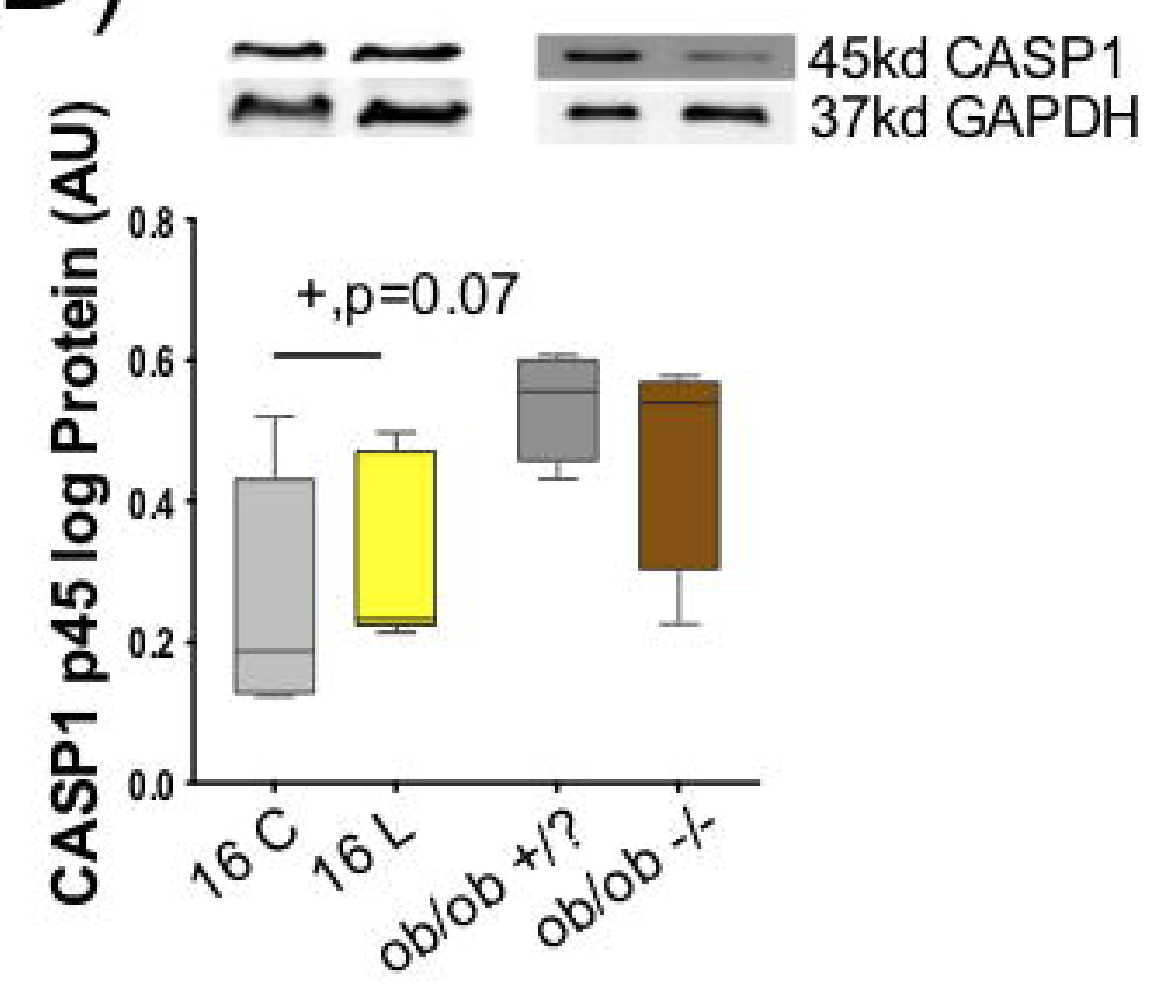

(F)

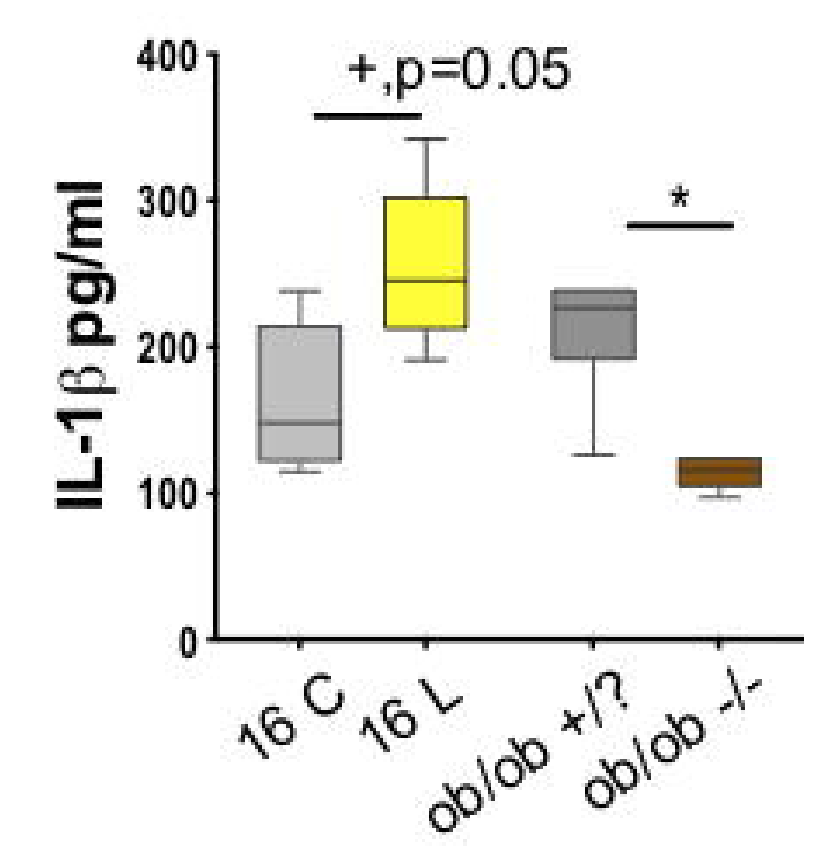


(A)

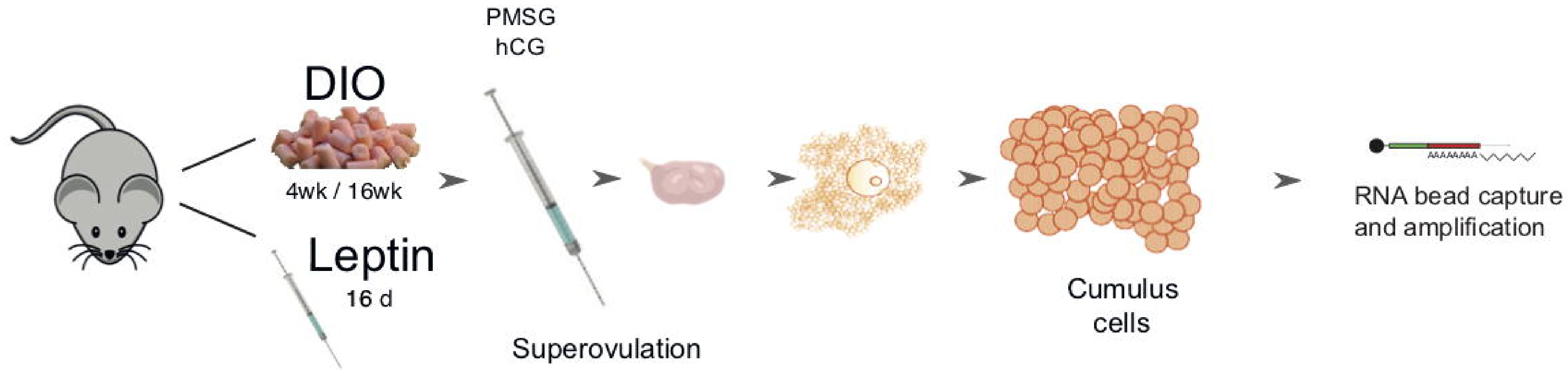

(B)

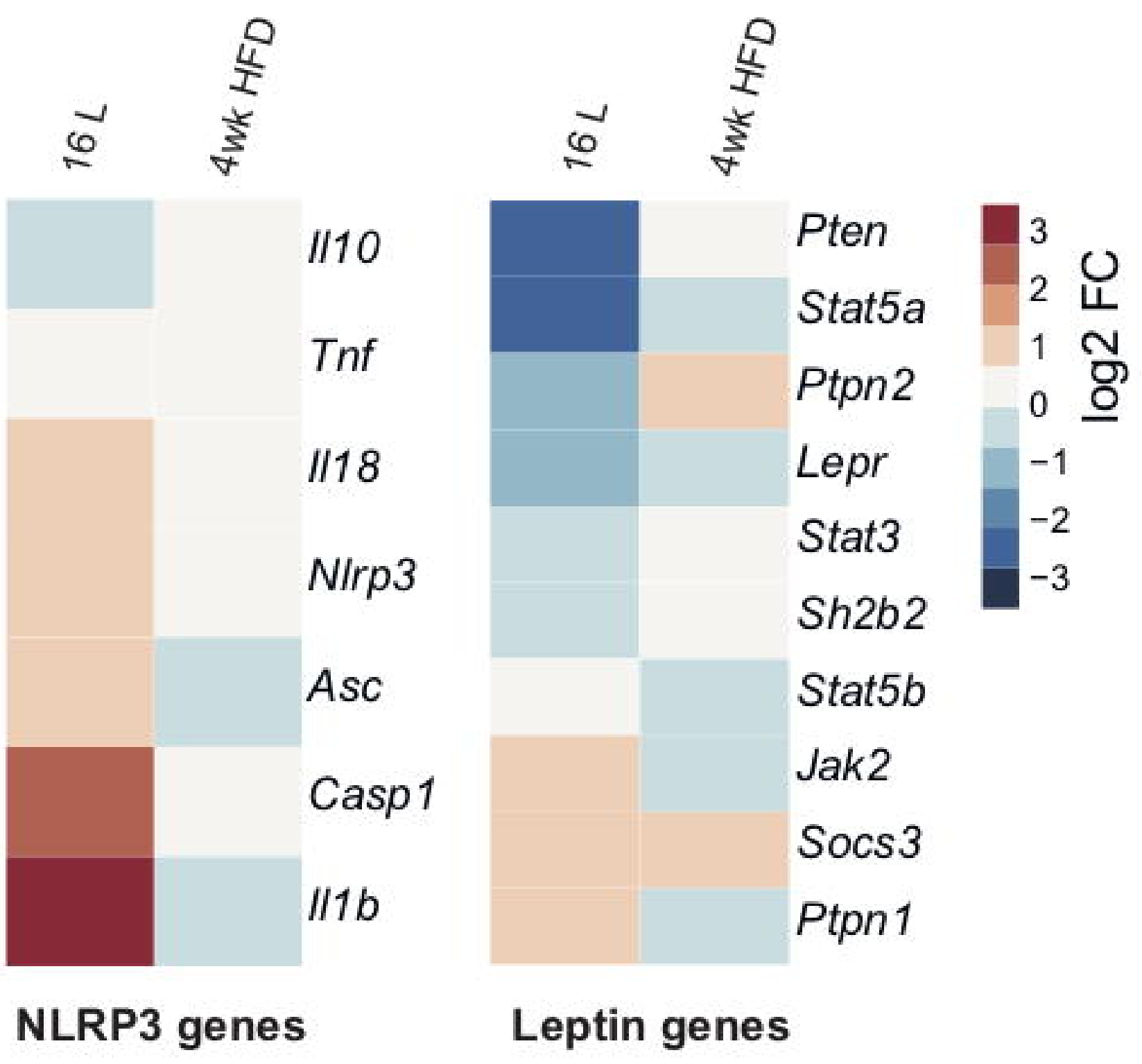

(C)

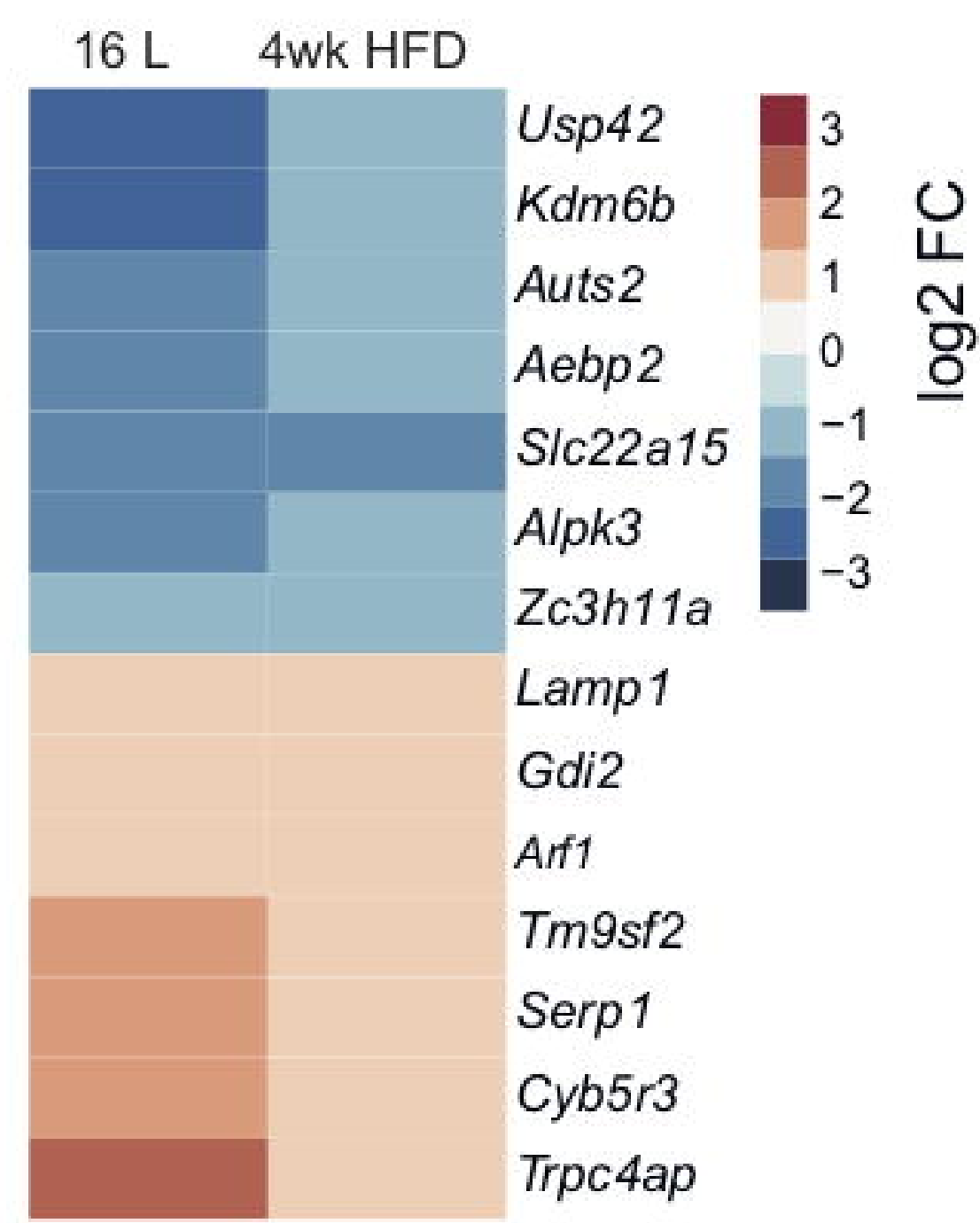

(D)

(E)

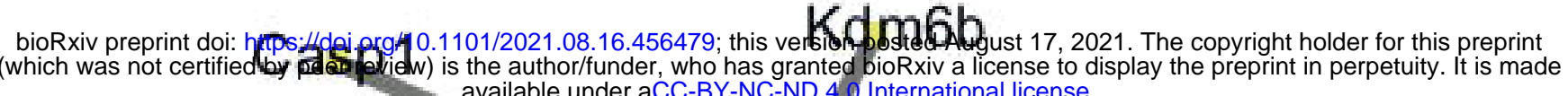
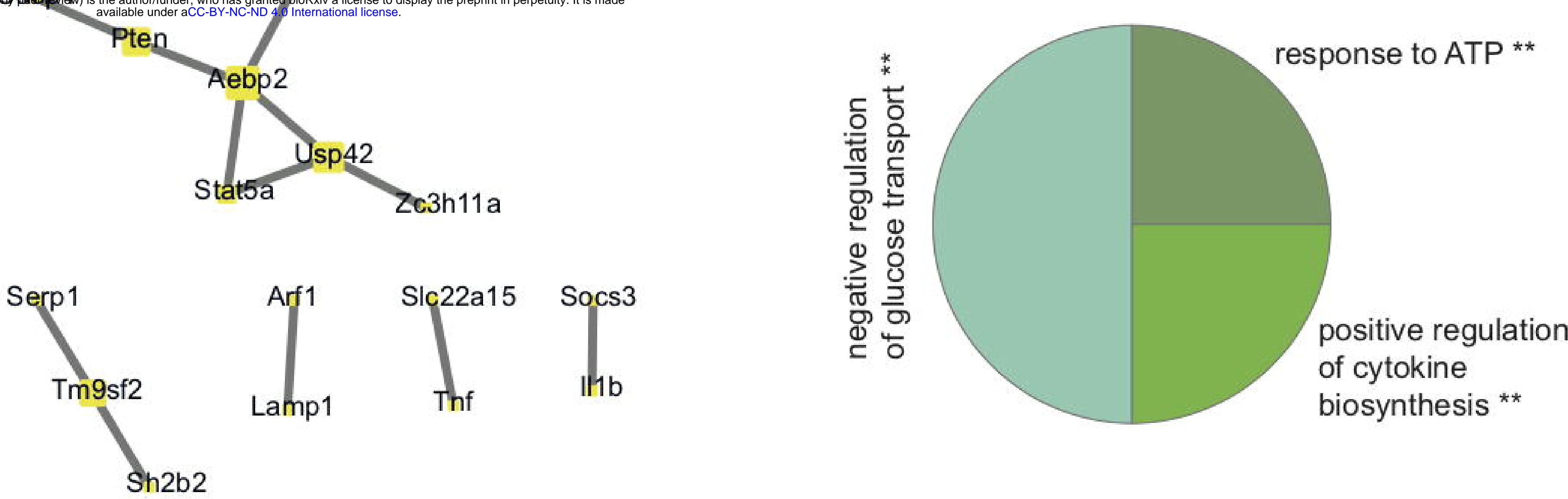

$(\mathrm{F})$
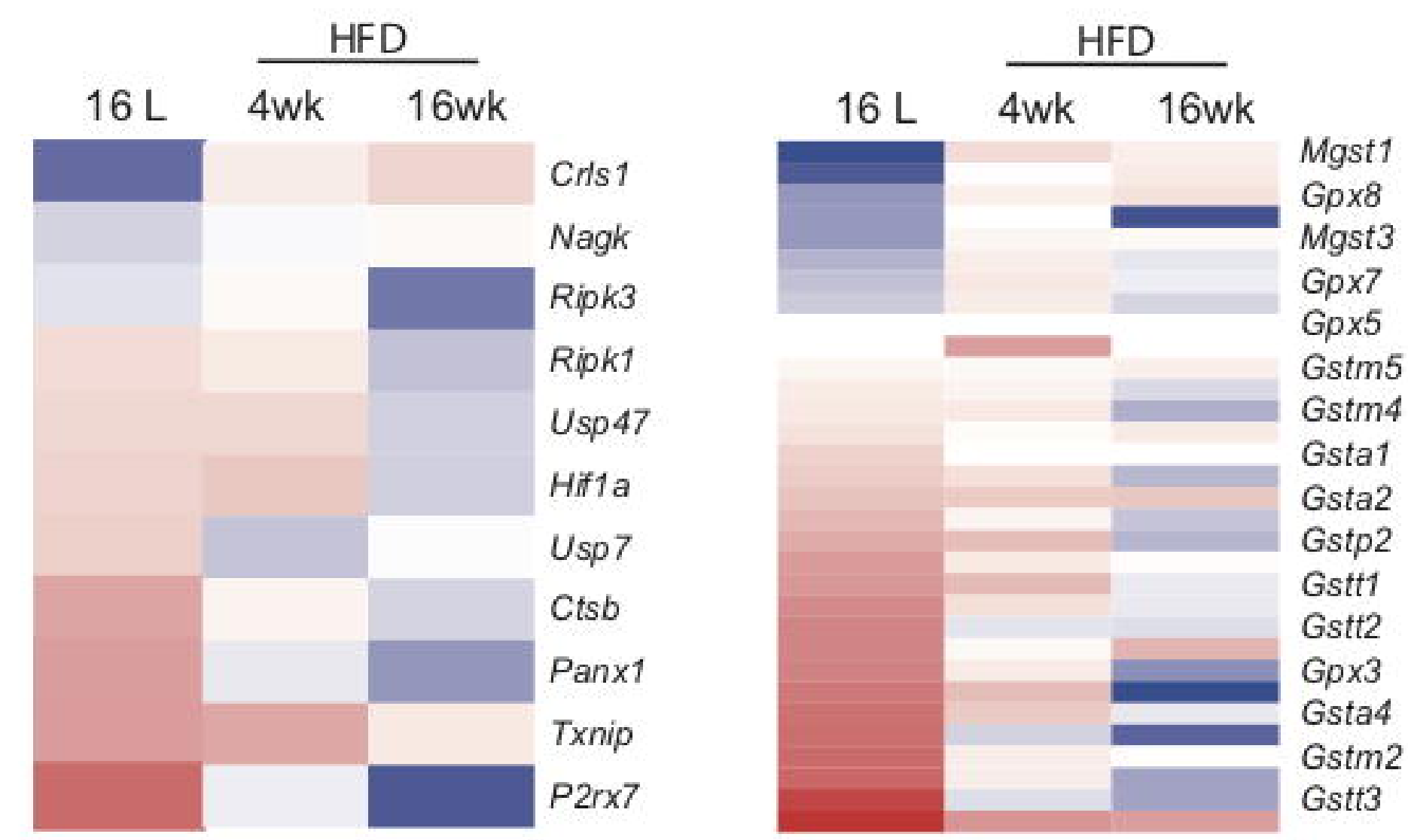

Activators

Gluthatione metabolism

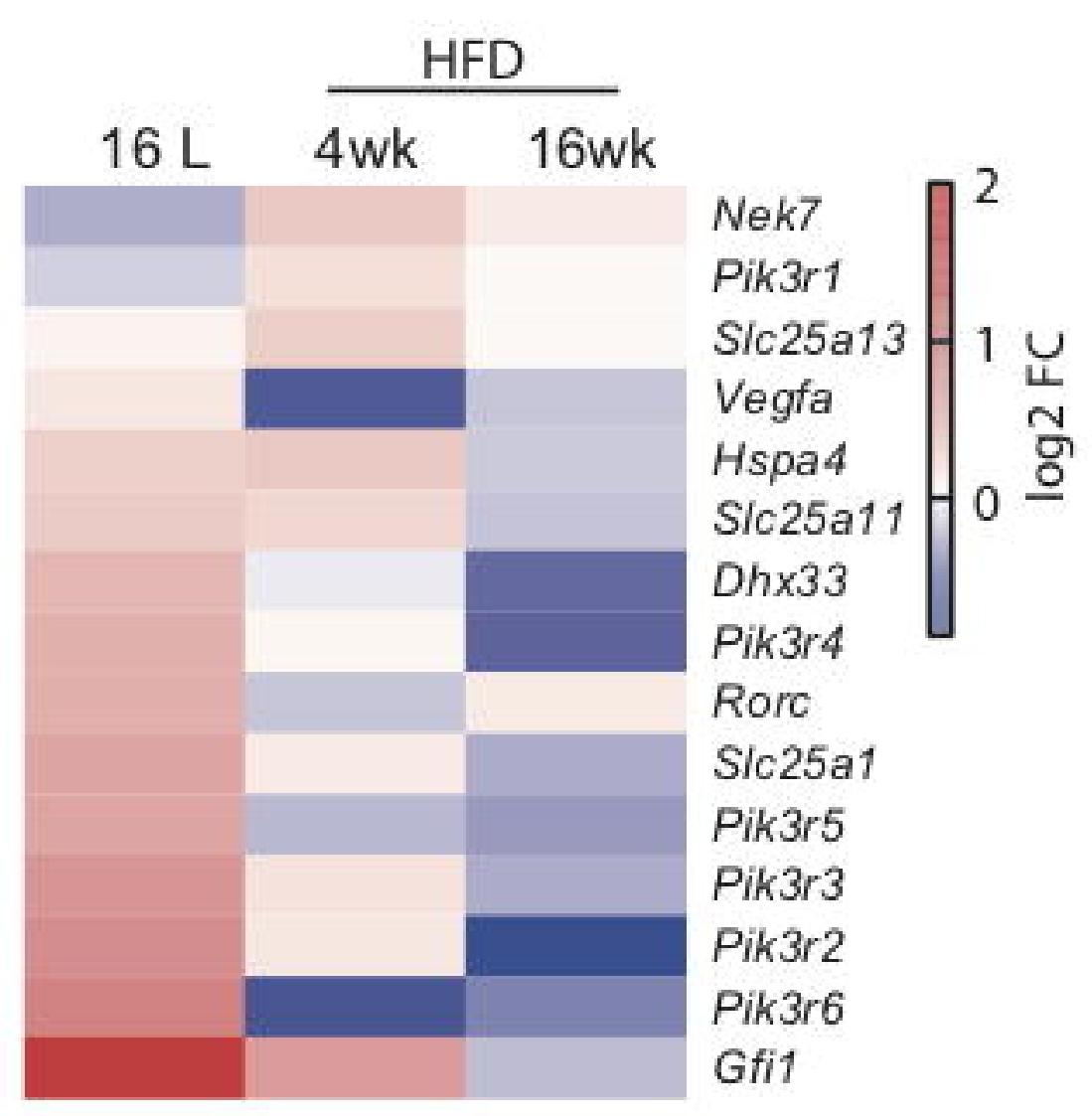

Other regulators 
(A)

(B)

HFD

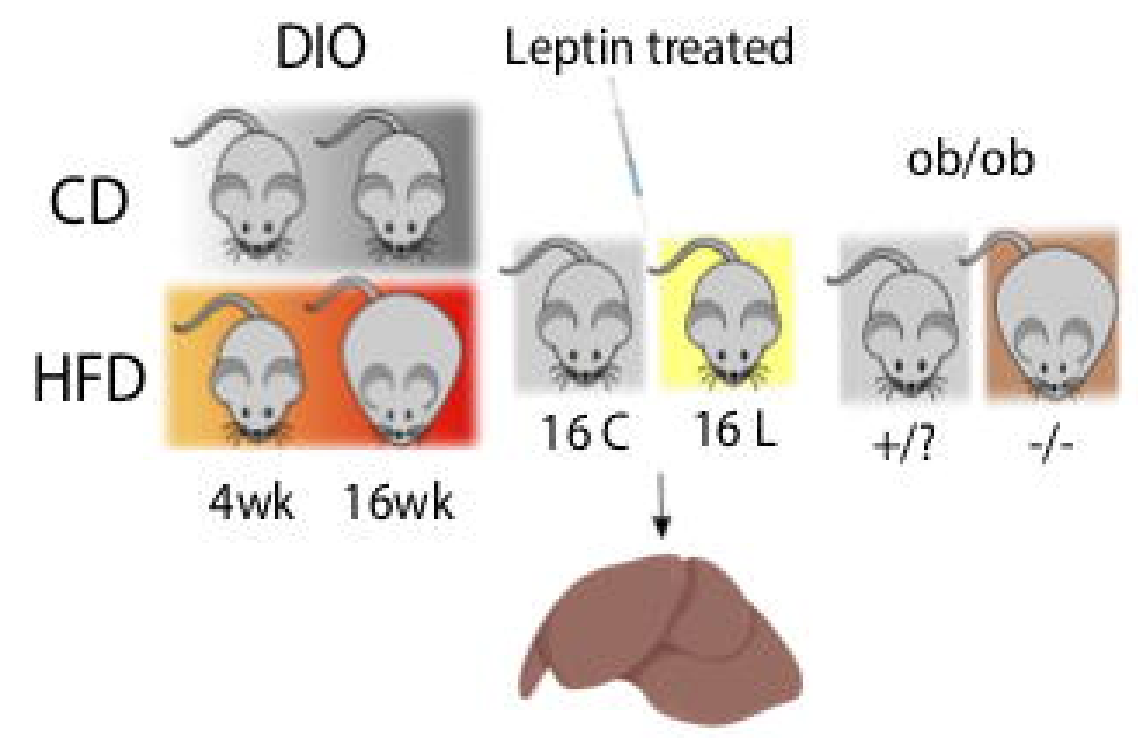

(C)

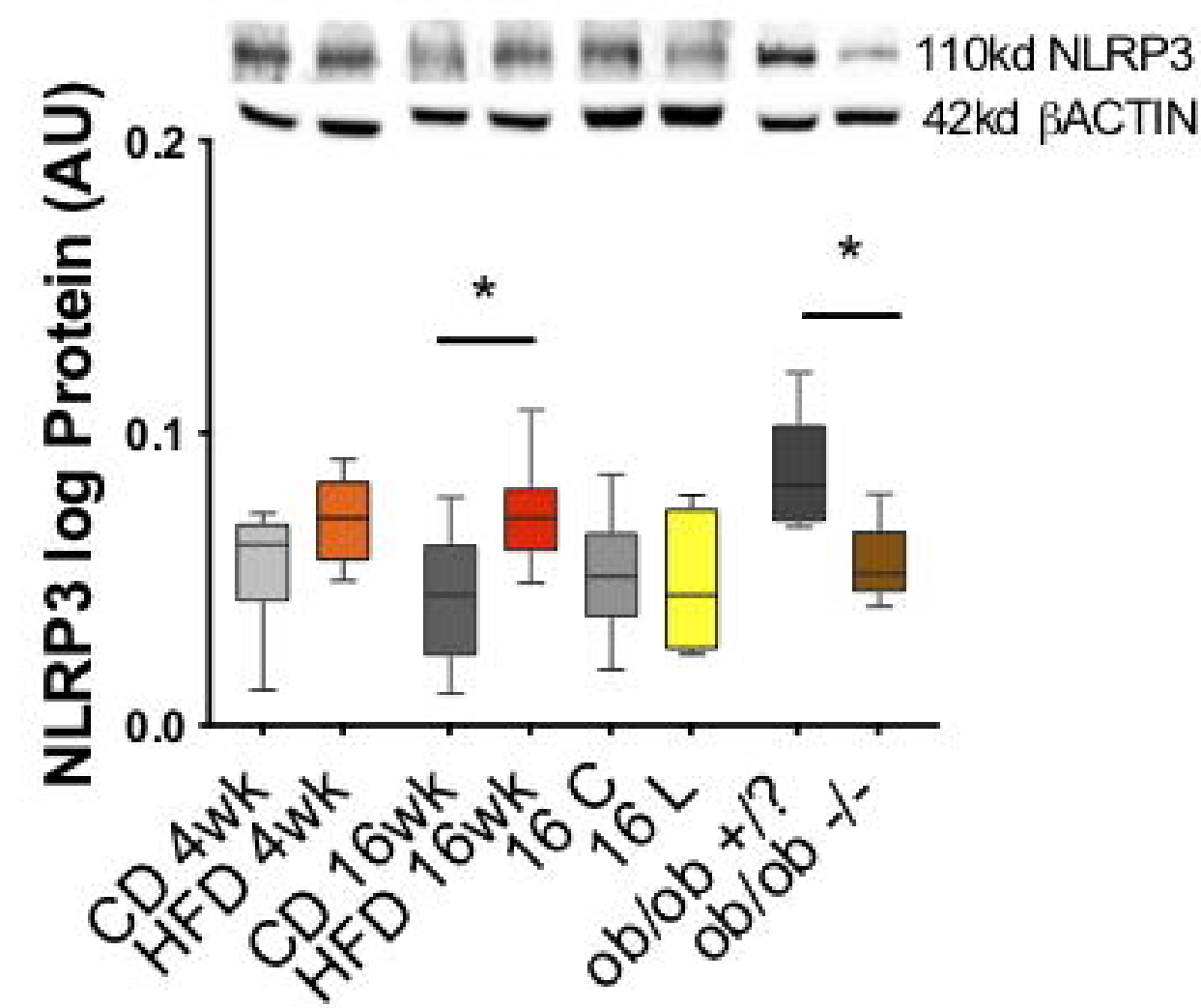

bioRxiv preprint doi: https://doi.org/10.1101/2021.08.16.456479; this version posted August 17, 2021. The copyright holder for this preprint

(D)

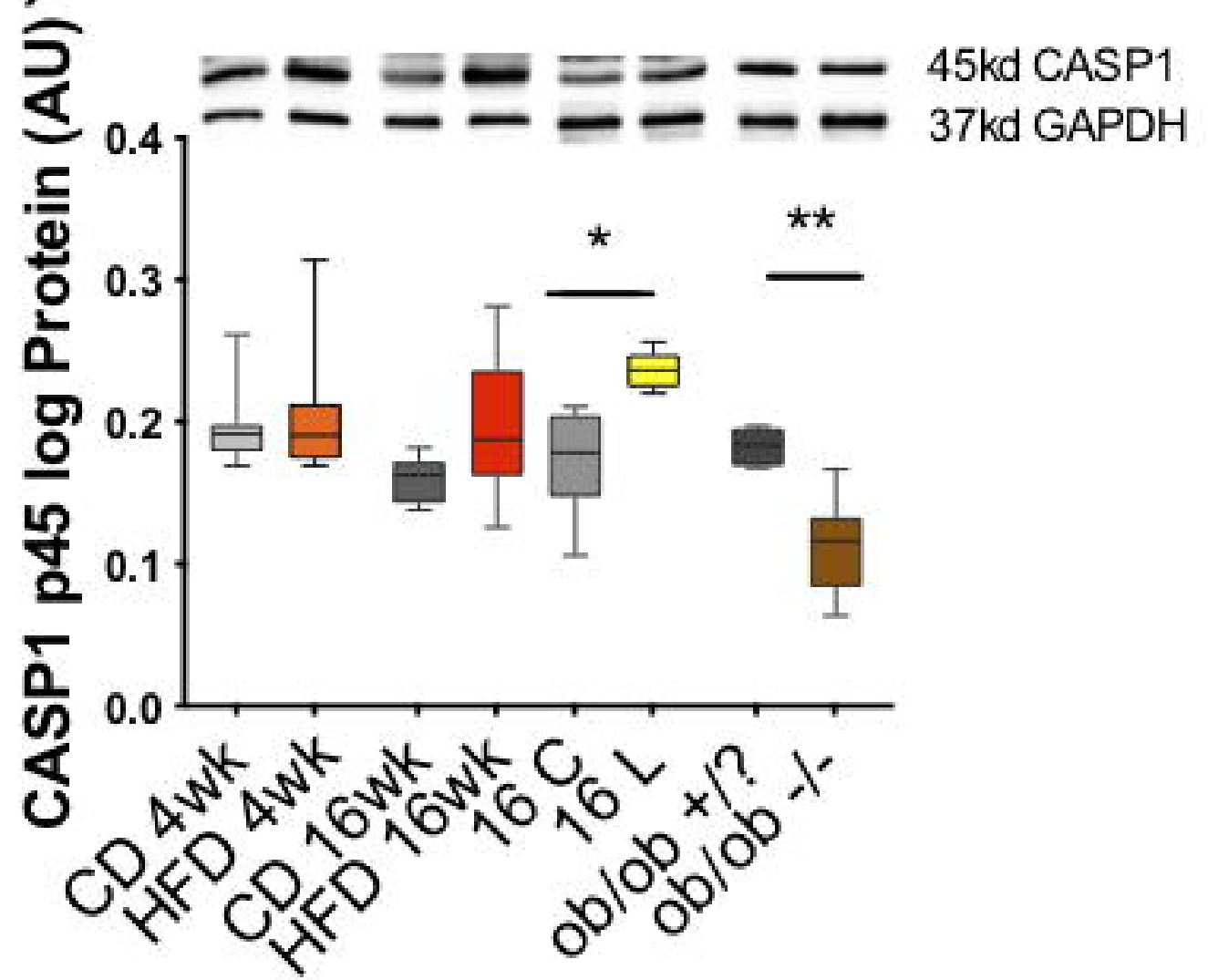

(F)

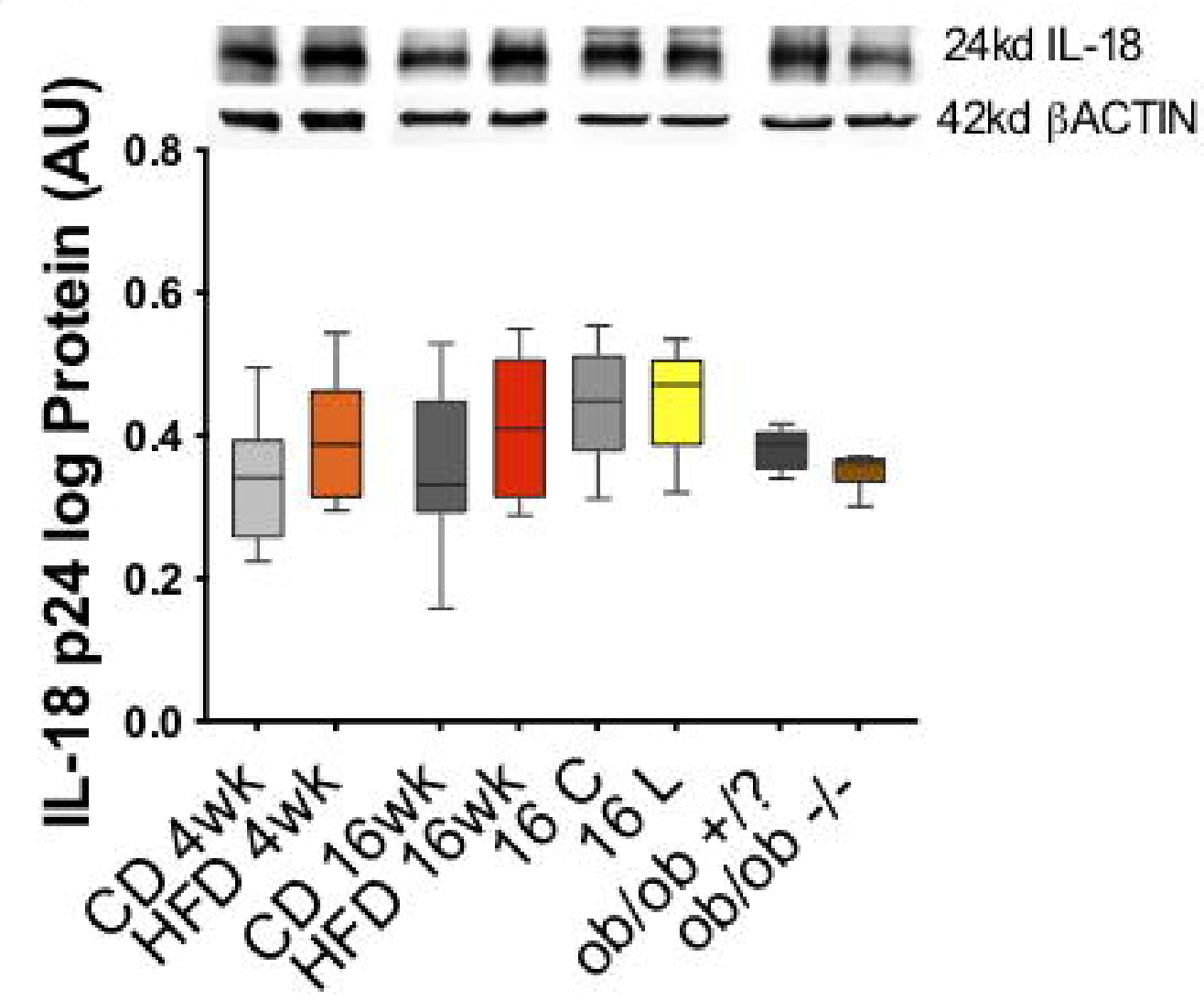

(E)

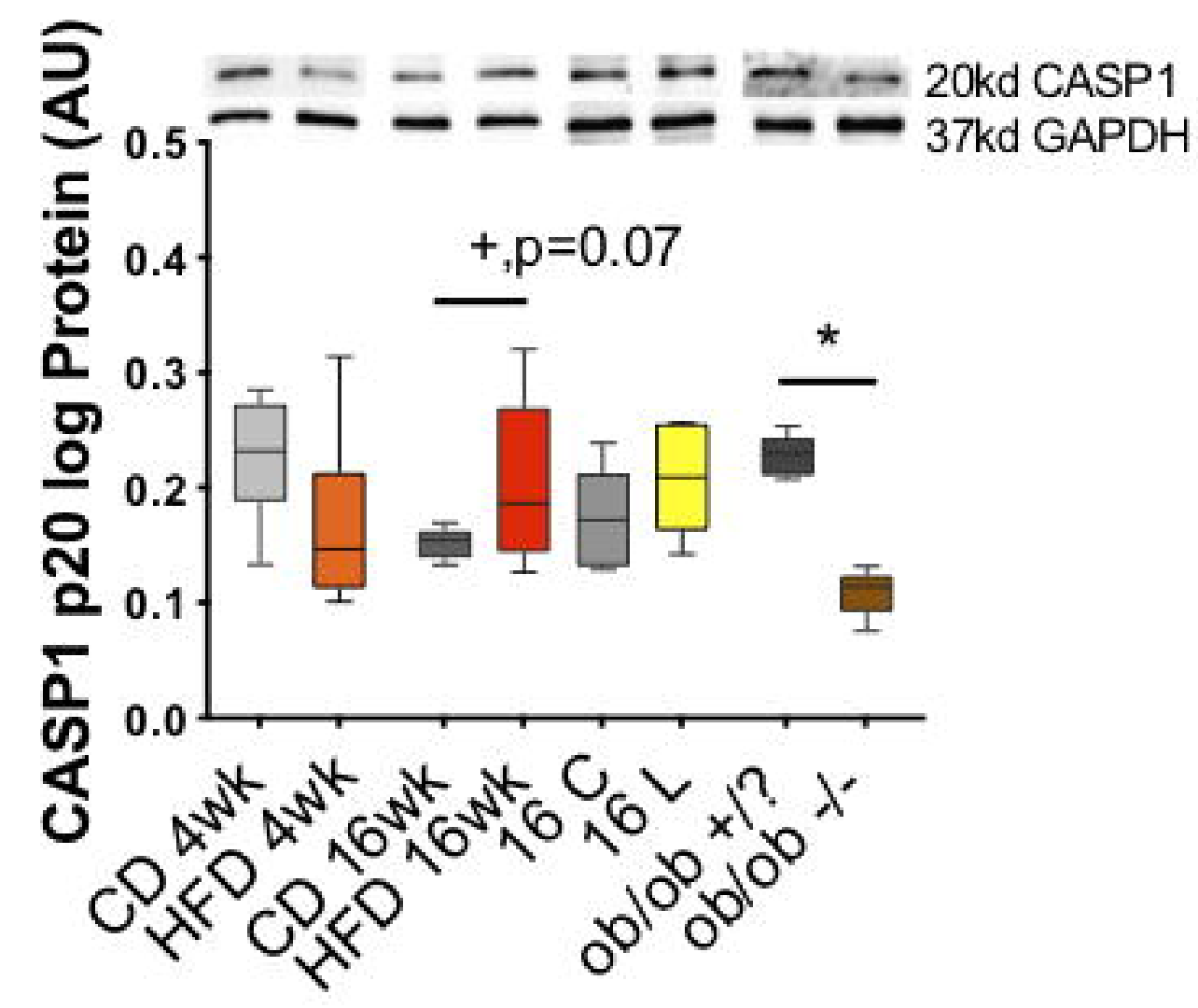

(G)

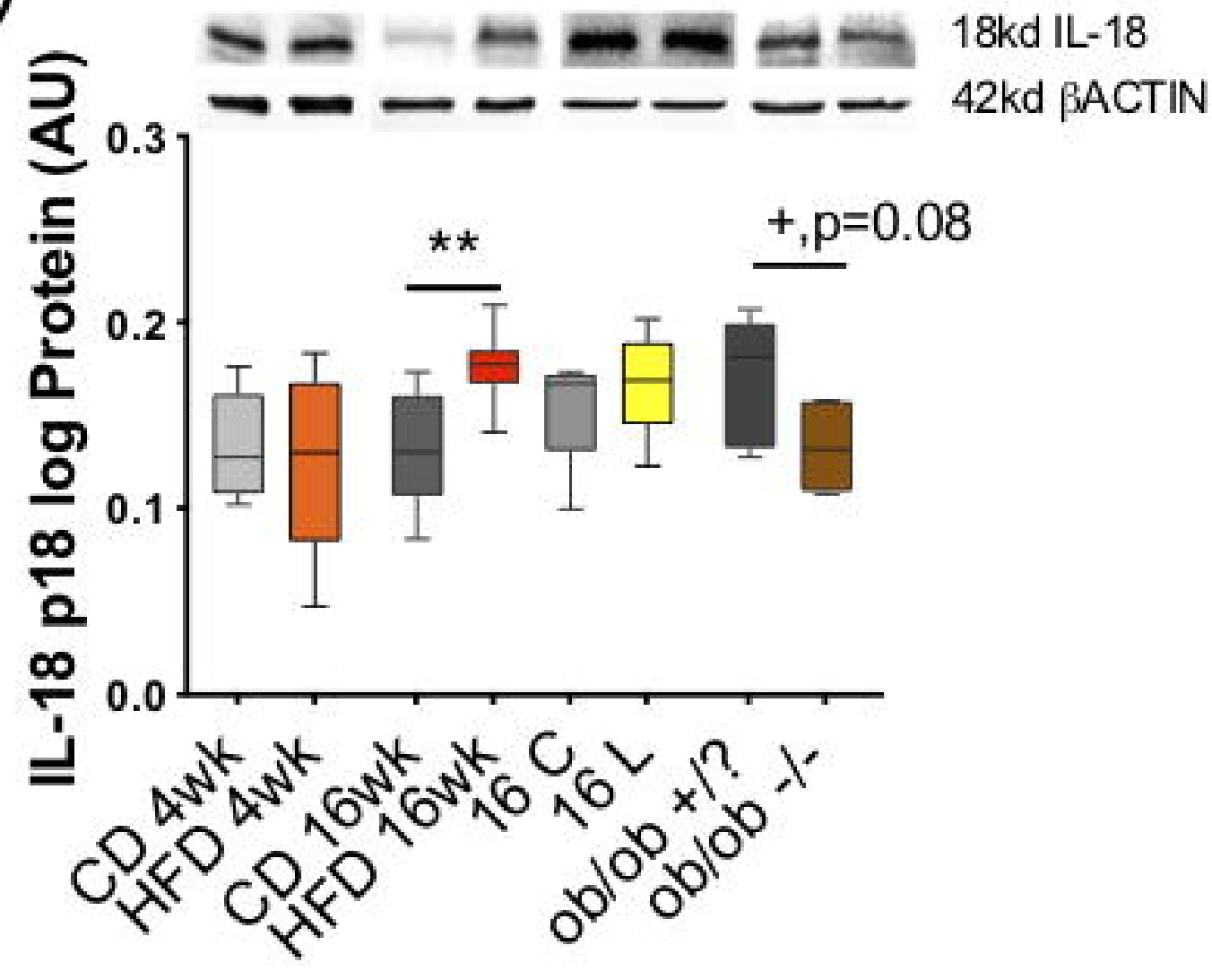

